Research Article

\title{
Determining Tensile Strength of Rock by the Direct Tensile, Brazilian Splitting, and Three-Point Bending Methods: A Comparative Study
}

\author{
Zhengjun Huang $\mathbb{D}^{1}{ }^{1}$ Ying Zhang, ${ }^{1}$ Yuan Li $₫$, ${ }^{1}$ Dong Zhang, ${ }^{1}$ Tong Yang, ${ }^{1}$ and Zhili Sui ${ }^{2}$ \\ ${ }^{1}$ School of Civil and Resource Engineering, University of Science and Technology Beijing, Beijing 100083, China \\ ${ }^{2}$ Urban Construction School, Beijing City University, Beijing 100083, China \\ Correspondence should be addressed to Zhengjun Huang; huang_jun.0518@163.com
}

Received 19 January 2021; Accepted 21 May 2021; Published 3 June 2021

Academic Editor: Castorina S. Vieira

Copyright (c) 2021 Zhengjun Huang et al. This is an open access article distributed under the Creative Commons Attribution License, which permits unrestricted use, distribution, and reproduction in any medium, provided the original work is properly cited.

\begin{abstract}
To accurately obtain the tensile strength of rock and fully understand the evolution process of rock failure is one of the key issues to the research of rock mechanics theories and rock mass engineering applications. Using direct tensile, Brazilian splitting, and threepoint bending test methods, we performed indoor and numerical simulation experiments on marble, granite, and diabase and investigated the tensile strength and damage evolution process of several typical rocks in the three different tests. Our experiments demonstrate that (1) the strength is about $10 \%$ greater in the Brazilian splitting than in the direct tensile, while the tensile modulus is lower; it is the highest in the three-point bending, which is actually subjected to the bending moment and suggested as one of the indexes to evaluate the tensile strength of rock; (2) the strength in splitting tests is strikingly different, while the strain law is basically similar; the direct tensile test with precut slits is more attainable than that with no-cut slits, with an uninfluenced strength; (3) the failure modes of rocks using different methods are featured by different lithology, while their final modes are basically the same under the same method; (4) PFC and RFPA numerical simulation tests are effective to analyze the internal crack multiplication and acoustic emission changes in the rock as well as the damage evolution process of rock in different tests.
\end{abstract}

\section{Introduction}

As a quasibrittle material, rock is possessed of some basic mechanical parameters or strength indicators, including compressive strength, tensile strength, and shear strength, among which the tensile strength is much lower than the compressive strength. In the recent decades, considerable researches have investigated the compressive behaviour of rock, while those on the tensile fracture of rock are rarely produced, due to the difficulty in obtaining the realistic tensile fracture behaviour. However, considering that in engineering practice, the tensile failure of rock is the main failure mode, and crack initiation and propagation under tensile stress are the major factors threatening the stability of rock engineering materials and structures, the tensile strength becomes one of the key mechanical parameters of rock, and its acquisition turns to be a reference for the design of underground engineering, such as mining, tunnels and water conservancy, and a disclosure of the rock failure mechanism $[1,2]$.

The test methods of rock tension are mainly classified into the direct and the indirect. Among them, the Brazilian disc splitting is the most common, while the direct tensile test is the most accurate and intuitive, which has been scarcely adopted, for the unfavourable rock sample processing and clamping connection. Some other indirect methods include circular ring splitting, bending, and point load $[3,4]$. As the traditional method, the direct tensile bonds the metal caps with the rock sample by using adhesive, while it is very likely to bring such problems as weak bonding and torsional stress $[5,6]$. For example, choosing this way to create "dog-bone"-shaped rock specimens, 
Klanphumeesri [7] failed to facilitate the specimen preparation and processing, although succeeding in the conversion of pressure into tension. Developing a new type of the direct tensile test device for eccentricity and torsion in the stretching process, Zhang et al. [8] did not solve the problem of bonding reliability. Comparatively, the Brazilian splitting method, based on the assumption of twodimensional plane stress, seems simple to operate and available to obtain results, thus attracting sufficient attention and achieving significant results. Hudson et al. [9] found that, due to the stress concentration at the loading point of the split test, the rock samples frequently cracked from this point rather than the central tensile stress zone, and then their tensile strength obtained became lower. Coviello et al. [10] discovered that the tensile strength of soft rocks obtained by using the Brazilian splitting method was lower than that by using the direct tensile. Based on quantities of test data analysis, Perras and Diederichs [11] obtained different ratios of direct tensile strength to Brazilian split tensile strength of different rocks. After observing the spatial tensile stress distribution in the Brazilian splitting test, Yu et al. [12, 13] suggested that the splitting method was inapplicable to obtaining the tensile strength of rock materials, since the rock sample was inevitably cracked from the loading point under the influence of stress concentration, the original calculation formula was unsuitable for the three-dimensional elasticity test, and the calculated strength was underestimated for rock engineering design. With the splitting test results under several different loading methods, He et al. [14] articulated the various reasons for their differences. With the improvement of the original Brazilian disc splitting test method in their study, Huang et al. [15] analyzed the Brazilian platform splitting to determine the rock tensile strength, finding that the rock sample betters the central fracture failure for an optimal platform loading angle. Comparing the direct tensile and splitting methods on the tensile strength of rock, Zhang et al. [1] concluded that the results obtained by the arc compression splitting method provide the upper limit of the tensile strength, while those by the angular pressure splitting reveal the lower limit, thus the direct tensile method is counted as the best.

Bending test for obtaining rock tensile strength is rarely used, due to the complexity of the bending load and the difficulty in specimen preparation. Chen [16] analyzed the tensile strength of rocks via three-point and four-point bending methods and uncovered the unreliability of the results in bending tests. Tong et al. [17] conducted experiments on marble, granite, sandstone, etc., using the three-point bending method and discovered the relationship between bending tensile strength and splitting tensile strength. Lv et al. [18] proposed a new method for determining the tensile strength of rock in bending test. Despite some development on rock tensile fracture study, it is still challenging to obtain the realistic tensile strength and fracture evolution process for different rocks in indoor experiments. Kittitep et al. employed numerical methods to analyze the initiating and expanding process of rock fracture in the disc split test, whose results were basically the same as those in the indoor tests. Literature demonstrates that in most current researches on the tensile strength, only one method has been adopted, while some uncertainty exists in the fracture evolution process of different rocks by different methods [19-25].

In this paper, we employed experimental and numerical methods to obtain the tensile strength and fracture evolution of granite, marble, and diabase. Considering that the direct tensile and Brazilian splitting test are highly recommended by test standards and widely used by researchers as well as tensile deformation conceivably results from the damage of the sample under three-point bending test, our experiments and simulation analysis prefer using the direct tensile, Brazilian splitting, and three-point bending methods. First, rock specimens are made to satisfy the corresponding requirements for the direct tensile, Brazilian splitting, and three-point bending tests. After collecting and comparing the tensile strength and elastic modulus of granite, marble, and diabase by the three testing methods, this study then investigates the strain development of marble specimens under the tests. Next is to obtain their respective failure modes for the specimens and develop their particle models for the specimens in PFC3D and RFPA. Then, it follows the comparison between the numerical and experimental results on the stress-strain curve of specimens and the discussion of the microcracks' development of rock using the three methods by simulations.

\section{Experimental Procedures}

2.1. Rock Specimens Preparation. The testing methods of direct tensile, Brazilian splitting (direct compression), and three-point bending are employed to get the difference of the tensile strength and damage deformation of rocks. The sample size by the three is processed according to the "Engineering Rock Mass Test Method Standard," "Water Conservancy and Hydropower Engineering Rock Test Regulations," and the International Society for Rock Mechanics (ISRM) recommended methods. The specifics are $50 \mathrm{~mm} \times 125 \mathrm{~mm}$ cylindrical samples in direct tensile, $50 \mathrm{~mm} \times 25 \mathrm{~mm}$ disc samples in Brazilian disc splitting, and $160 \mathrm{~mm} \times 40 \mathrm{~mm} \times 20 \mathrm{~mm}$ long strip samples in three-point bending. The processing accuracy of all samples is performed in accordance with the requirements of ISRM and other standards [26-28], while the number of different lithological rock samples and the main physical and mechanical parameters (average values) are shown in Table 1.

2.2. Loading Equipment and Test Methods. In the test, the WEP-600 universal material testing machine is used for loading (Figure 1), and the DH3820 static strain gauge was used for recording the strain of the rock samples during the loading process. The test process is controlled with load, the loading speeds correspond to the direct tensile, disc splitting, and three-point bending tests, respectively, $0.5 \mathrm{kN} / \mathrm{s}, 0.3 \mathrm{kN} /$ $\mathrm{s}$, and $5 \mathrm{~N} / \mathrm{s}$. Figure 2 reveals the loading method of the three different methods [29]. 
TABLE 1: Number of samples and main parameters for different rocks.

\begin{tabular}{|c|c|c|c|c|c|c|}
\hline Lithology & $\begin{array}{l}\text { Number of } \\
\text { samples }\end{array}$ & $\begin{array}{l}\text { Natural density, } \rho_{0} \\
\left(\mathrm{~g} . \mathrm{cm}^{-3}\right)\end{array}$ & $\begin{array}{c}\text { Moisture content, } \\
w_{0}(\%)\end{array}$ & $\begin{array}{c}\text { Porosity, } n \\
(\%)\end{array}$ & $\begin{array}{l}\text { Longitudinal wave } \\
\text { velocity, } V_{p}(\mathrm{~m} / \mathrm{s})\end{array}$ & $\begin{array}{c}\text { Dynamic elastic } \\
\text { modulus, } E_{\mathrm{d} t}(\mathrm{GPa})\end{array}$ \\
\hline Granite & $\begin{array}{l}\text { Cylinder: } 5 \\
\text { Disc: } 4 \\
\text { Cuboid: } 5\end{array}$ & 2.619 & 0.03 & 2.09 & 4512 & 53.38 \\
\hline Marble & $\begin{array}{l}\text { Cylinder: } 6 \\
\text { Disc: } 6 \\
\text { Cuboid: } 5\end{array}$ & 2.835 & 0.11 & 2.03 & 4029 & 46.02 \\
\hline Diabase & $\begin{array}{l}\text { Cylinder: } 5 \\
\text { Disc: } 4 \\
\text { Cuboid: } 4\end{array}$ & 2.144 & 2.43 & 21.71 & 2406 & 12.45 \\
\hline
\end{tabular}

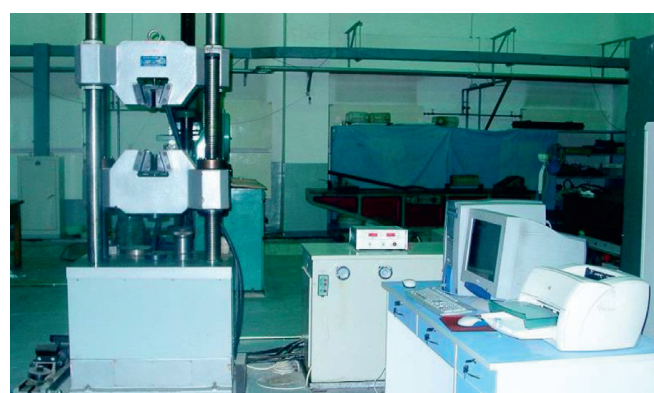

(a)

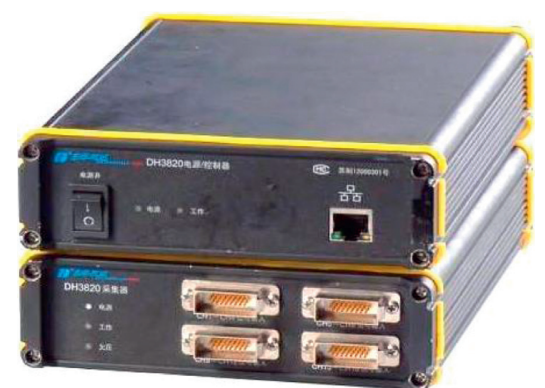

(b)

FIgure 1: WEP-600 Universal Material Testing Machine and DH3820 strain collector.

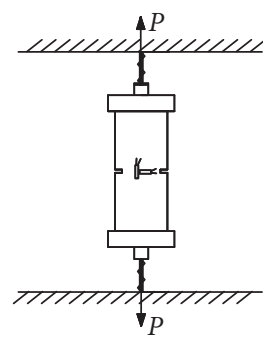

(a)

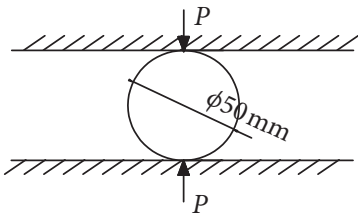

(b)

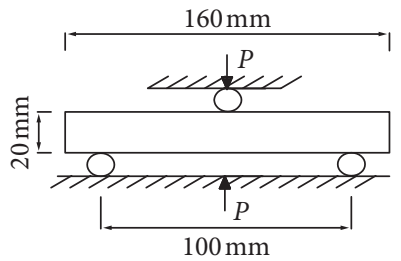

(c)

Figure 2: Schematic diagram of three different test methods. (a) Direct tensile test. (b) Brazilian splitting test. (c) Three-point bending test.

In addition, in the direct tensile test, the rock sample is bonded with the metal cap with epoxy glue to ensure that the rock sample will be broken, and two cracks are prefabricated on both sides of the middle, with a depth of $10 \mathrm{~mm}$ and a width of $2 \mathrm{~mm}$. Strain gauges are pasted along the diameter and split failure direction in the middle of the direct tensile and Brazilian splitting specimens, respectively, while they are pasted in the bottom middle of the three-point bending specimens to measure the tensile strain during the loading.

\subsection{Stress-Strain Characteristic Tests under Direct Tensile} and Brazilian Split Test. To investigate the stress-strain characteristics of the rock samples at different positions and times in the direct tensile and Brazilian splitting tests, we paste the strain gauges at different positions when performing their loading with marble samples. Their stressstrain characteristic values are recorded and compared using the subsequent numerical simulation test. The specific test methods are shown in Figures 3 and 4 .

\section{Experimental Results and Analysis}

3.1. Analysis of Rock Tensile Strength and Elastic Modulus. The calculation methods of rock tensile strength and elastic modulus with different experimental methods are expressed as the following formulas: 


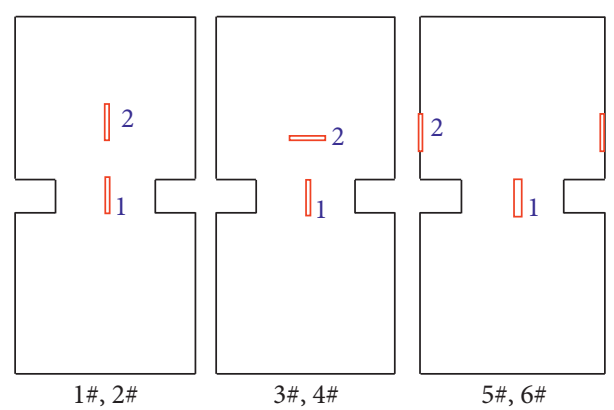

FIGURE 3: Strain monitor of different positions in direct tensile test. Description: 1-position 1, the middle of the sample; 2-position 2, 20 mm upper of the middle of the sample.

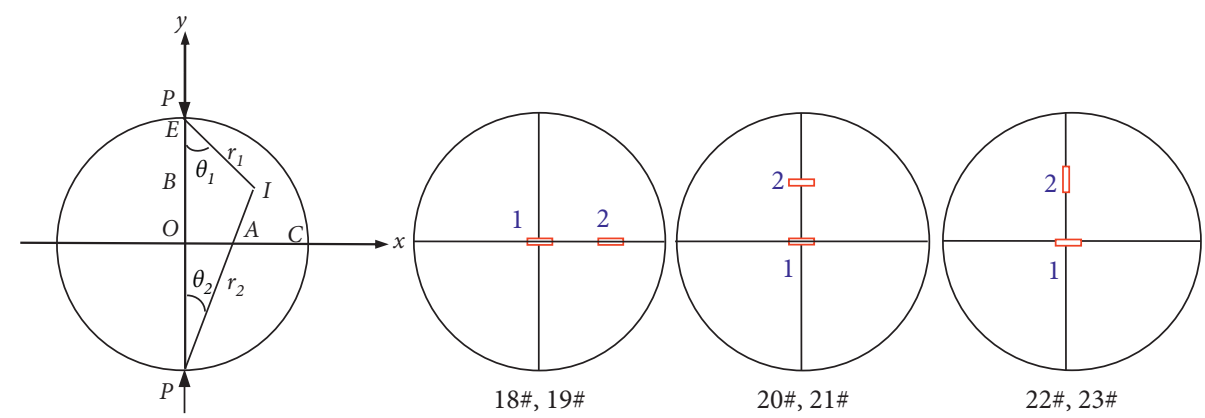

Figure 4: Strain monitor of different positions in Brazilian disc split test. Description: 1-position 1, the center of the sample; 2-position 2, 1/4 diameter away from the center.

$$
\begin{gathered}
\sigma_{\mathrm{d} t}=\frac{P_{\max }}{A}, \\
\sigma_{s t}=\frac{2 P_{\max }}{\pi D H}, \\
\sigma_{b t}=\frac{3 P_{\max } L}{2 b h^{2}} \\
\text { or } \frac{M C}{I} \\
E_{t}=\frac{\sigma_{t 50}}{\varepsilon_{t 50}} .
\end{gathered}
$$

Among them, $\sigma_{\mathrm{d} t}, \sigma_{s t}$, and $\sigma_{b t}$ are the tensile strength of the rock under direct tensile, Brazilian splitting, and threepoint bending, respectively; $E_{t}$ is the elastic modulus; $P$ is the maximum failure load; $D$ and $H$ are the sample diameters and height, respectively; $L$ is the support span, take $120 \mathrm{~mm}$; $b$ and $h$ are the width and height of the bending specimen; $M$ is the maximum bending moment acting on the section of the specimen; $C$ is the distance from the edge of the specimen to the neutral axis; $I$ is the moment of inertia of the beam section around the neutral axis.

According to formulas (1)-(4), samples of different lithology with different test methods are calculated, as shown in Table 2, and the stress-strain curves of some samples are formed, as shown in Figure 5. In the light of the unanimously recognized methods and results, the accurate values of the rock tensile strength are determined using direct tensile.
Table 3 presents those with the Brazilian splitting and the three-point bending methods after the measurement and comparative analysis.

Besides, Tables 2 and 3 altogether indicate that the tensile strength of the rock with the disc splitting method is greater than that with the direct tensile method, whose ratio is basically 1.1-1.2, while the elastic modulus in the former type of test is about $0.5-0.7$ of that in the latter. It is noted that the strength in the three-point bending tests is about 1.6-2.8 times of that in the direct tensile tests, while its elastic modulus is lower, with the ratio being about 0.8 0.9. This might be contributed to the assumption of elastic mechanics plane strain in the disc splitting tests, which says that the disc rock sample is cracked from the maximum tensile stress in the center. However, according to $\mathrm{Yu}$ and Chen [13], it will be accessible to investigate Brazilian disc splitting from the perspective of the three-dimensional stress distribution. Another possible reason might be the stress concentration at the loading point, which triggers the cracks and finally the failure in rock. Moreover, according to the Poisson effect, the tensile stress gradually decreases from the center of the circle to the outer circumference in the direction of the maximum diameter, which produces a smaller actual tensile strain and then a larger modulus. Comparatively, in the three-point bending tests, the rock sample is subjected to bending moments rather than pure tensile stress, both tensile and compressive stresses happen on the cross-section of the sample, with the position of neutral axis being about 0.44 of the sample height [16]. Despite a starting of the final failure with tensile fracture 
TABle 2: Test results of different lithology samples with different methods.

\begin{tabular}{|c|c|c|c|c|c|c|}
\hline \multirow[b]{2}{*}{ Lithology } & \multicolumn{2}{|c|}{ Direct tensile } & \multicolumn{2}{|c|}{ Brazilian splitting } & \multicolumn{2}{|c|}{ Three-point bending } \\
\hline & $\begin{array}{l}\text { Tensile strength, } \sigma_{\mathrm{d} t} \\
(\mathrm{MPa})\end{array}$ & $\begin{array}{c}\text { Elastic modulus, } \\
E_{\mathrm{d} t}(\mathrm{GPa})\end{array}$ & $\begin{array}{l}\text { Tensile strength, } \sigma_{s t} \\
(\mathrm{MPa})\end{array}$ & $\begin{array}{c}\text { Elastic modulus, } E_{s t} \\
(\mathrm{GPa})\end{array}$ & $\begin{array}{l}\text { Tensile strength, } \sigma_{b t} \\
(\mathrm{MPa})\end{array}$ & $\begin{array}{c}\text { Elastic modulus, } E_{b t} \\
(\mathrm{GPa})\end{array}$ \\
\hline Granite & 7.70 & 63.00 & 8.74 & 39.00 & 21.14 & 53.55 \\
\hline Marble & 5.84 & 33.16 & 6.84 & 18.60 & 9.46 & 27.78 \\
\hline Diabase & 5.67 & 49.92 & 6.61 & 34.78 & 10.60 & 44.73 \\
\hline
\end{tabular}

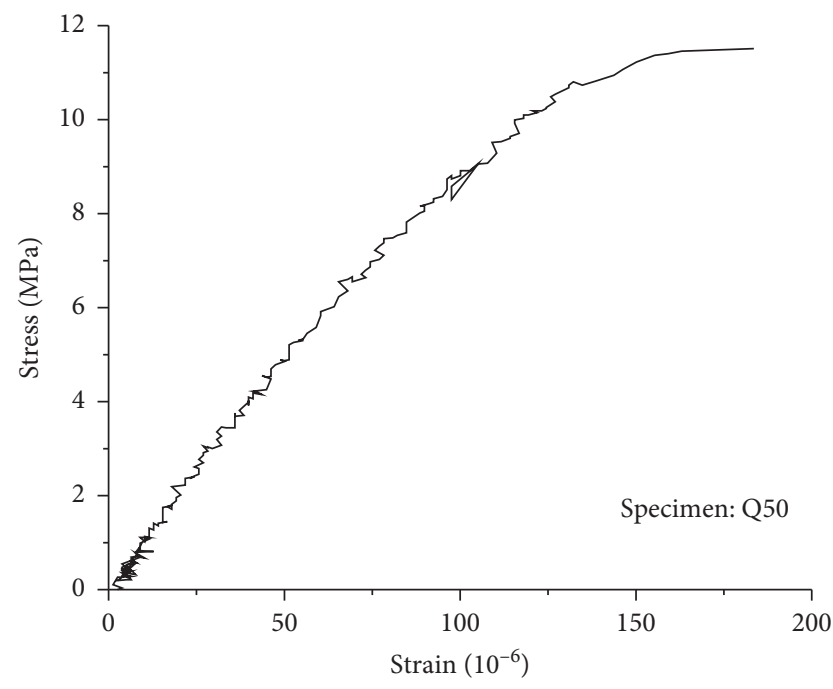

(a)

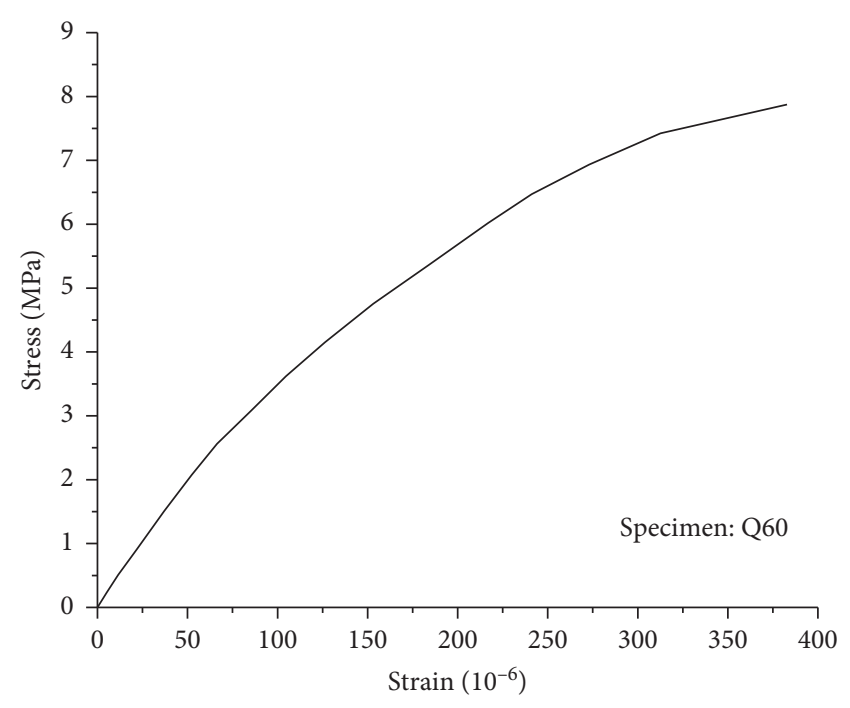

(b)

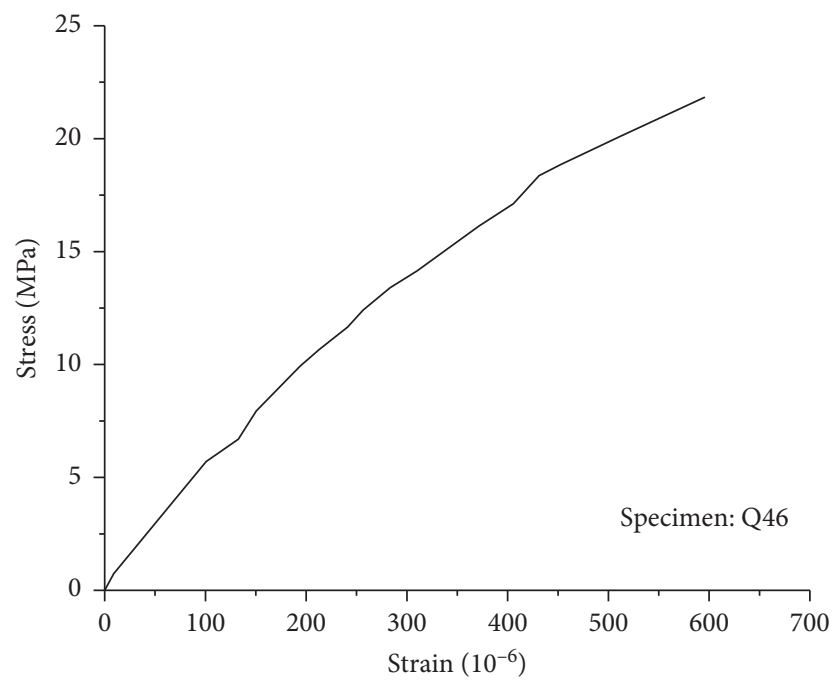

(c)

FIGURE 5: Stress-strain curves of some rock samples with different methods. (a) Direct tensile test. (b) Brazilian splitting test. (c) Three-point bending test.

TABLE 3: Results of comparative analysis with different methods.

\begin{tabular}{lcccr}
\hline \multirow{2}{*}{ Lithology } & \multicolumn{2}{c}{ Brazilian splitting } & \multicolumn{2}{c}{ Three-point bending } \\
& Intensity ratio & Modulus ratio & Intensity ratio & Modulus ratio \\
\hline Granite & 1.135 & 0.619 & 2.745 & 0.850 \\
Marble & 1.171 & 0.561 & 1.620 & 0.838 \\
Diabase & 1.166 & 0.697 & 1.869 & 0.896 \\
\hline
\end{tabular}


from the bottom, there still occurs a greater strength in these tests than in the direct tensile, precisely, a greater rock flexural strength or bending tensile strength. Besides, the uneven distribution of tensile stress and strain at the bottom of the rock sample causes its slighter actual tensile strain. Therefore, the measured modulus in bending tests is smaller than that in the direct tensile tests.

\subsection{Stress-Strain Analysis for Specimens under the Brazilian} Splitting and Direct Tensile Tests. Figure 3 depicts the $x-y$ coordinate system with the center as the origin and the crosssection of the disc sample with diameter $d$ and thickness $t$. Accordingly, with the application of the concentrated load $P$ to the sample under the condition of radial compression, the stress at a point $I(x, y)$ can be shown as follows:

$$
\begin{gathered}
\sigma_{x}=\frac{2 P}{\pi t}\left(\frac{\sin ^{2} \theta_{1} \cdot \cos \theta_{1}}{r_{1}}+\frac{\sin ^{2} \theta_{2} \cdot \cos \theta_{2}}{r_{2}}\right)-\frac{2 P}{\pi \mathrm{d} t}, \\
\sigma_{y}=\frac{2 P}{\pi t}\left(\frac{\cos ^{3} \theta_{1}}{r_{1}}+\frac{\cos ^{3} \theta_{2}}{r_{2}}\right)-\frac{2 P}{\pi \mathrm{d} t}, \\
\tau_{x y}=\frac{2 P}{\pi t}\left(\frac{\cos ^{2} \theta_{1} \cdot \sin \theta_{1}}{r_{1}}+\frac{\cos ^{2} \theta_{2} \cdot \sin \theta_{2}}{r_{2}}\right) .
\end{gathered}
$$

Then, based on equations (5)-(7), the stress of the sample section in different positions is calculated, and its relationship with strain in specific positions is shown in Table 4.

Considering the homogeneity of marble specimens, we conduct an in-depth experimental study on marble for the stress-strain evolution. Here, it should be mentioned that in our study, cyclic loadings for loading are employed to examine marbles 19 23 in 1 to 3 cycles during the loading process in order to observe the strain hysteresis characteristics of the rock sample as well as the deformation and expansion of the rock along the original stress path. Figure 5 shows the strain measurement results at different positions of the rock samples, while Table 5 reveals the results of the split test of the 6 marbles in this part. Moreover, Figure 6 displays the stress-strain curves at different positions.

As is seen in Table 5 and Figure 6, the splitting tensile strength varies from $4.8 \mathrm{MPa}$ to $10.09 \mathrm{MPa}$ for different marble specimens, while the difference of the tensile elastic modulus at the central position is smaller than that of the strength, which is basically $17-20 \mathrm{GPa}$. Specifically, Figures $6(a)-6(d)$ show that, from the point of view of the modulus, marbles $18-19$ are about $20-30 \%$ greater at the $1 / 4$ diameter away from the center in the horizontal radial direction $\left(E_{2}\right)$ than in the center of rock sample $\left(E_{t}\right)$, while marbles $20-21$ at the $1 / 4$ diameter in the vertical radial direction $\left(E_{2}\right)$ is basically consistent with the center $\left(E_{t}\right)$. It implies that notwithstanding the inconsistency in the tensile strength of the rock samples, the strain law still stands among the different rock samples at the same position and the strain energy stored of different positions remains the same under cyclic tensile load. Furthermore, with the increase of the load, the plastic strain energy stored becomes gradually larger, while its ultimate tensile strain is not much different. However, according to Figures 6(e) and 6(f), the tensile modulus of marbles $22 \sim 23$ is basically unchanged along the vertical load direction, while their compressive modulus $\left(E_{2}\right)$ is greater than the tensile modulus $\left(E_{t}\right)$, with 1.5-2.5 times of it, which indicates that the tensile and compressive strain vary with the stress.

Similarly, Table 6 delivers the results of the direct tensile test with prefabricated slits on the same batch of marble samples based on the test method and formula (1) in Section 2.3. For the marble samples, the tensile strength under direct tensile is about $5-6 \mathrm{MPa}$, with an average of about $5.70 \mathrm{MPa}$, which is generally consistent with the results in Table 2, while the elastic modulus is similar to the previous, indicating a good uniformity of these samples.

In addition, Figure 8 shows the photos of some samples before and after the test, and Figure 9 describes the stressstrain curves of the rock samples of marbles 1-6. In detail, based on marble 1, marbles 3-4 in Figures 9(a), 9(c), and 9(d) provided that they stay at the same axis, the tensile elastic modulus will keep generally unchanged, whether it is in the middle or the upper $1 / 4$ position of the rock sample. Moreover, Figure 9(b) shows that under the influence of the Poisson effect during the direct tensile process, the surface of the rock sample produces compressive strain, whose value is much smaller than the tensile strain, about 1/10, while Figures 9(e) and 9(f) indicate that, due to the influence of the crack, the tensile deformation at the upper and lower ends of the crack is much smaller than that in the intact middle part.

\subsection{Characteristic Analysis of Rock Sample after Failure.} Figures 6, 8, and 10 depict the failure mode of the specimens by the three testing methods. Due to the prefabricated cracks, the rock samples fracture from the middle or upper middle of the rock samples under direct tensile, and their surface is basically flat but sometimes slightly uneven (the larger the internal mineral grain size, the more obvious it is, such as granite), attributed to the crystal chain fracture between the internal mineral composition and structure. Contrastively, along the diameter direction, most fractures of the disc splitting rock samples are linear, but a few are curvilinear. The stress concentration effects clearly "V"shaped compression failure zones in the loading areas at both ends. In the three-point bending tests, the rock samples initially crack from the bottom with tension fracture and then form a new linear main crack, which results in a larger tensile strength.

3.4. Numerical Simulation Test Verification. The fracture time of the rock under loading is too short, commonly in milliseconds, which raises an extreme difficulty in overseeing the fracture process of rock samples in different loading tests. Therefore, to further analyze the strength characteristics and damage evolution process of the rock with different test methods, this study introduces the PFC3D 
TABLE 4: Stress value of the split tensile specimens in specific positions.

\begin{tabular}{|c|c|c|c|c|c|c|c|c|c|}
\hline \multirow{2}{*}{ Position } & \multicolumn{6}{|c|}{ The relationship between position coordinates and force points } & \multirow{2}{*}{$\sigma_{x}$} & \multirow{2}{*}{$\sigma_{y}$} & \multirow{2}{*}{ Remarks } \\
\hline & $x$ & $y$ & $r_{1}$ & $r_{2}$ & $\theta_{1}\left({ }^{\circ}\right)$ & $\theta_{2}\left({ }^{\circ}\right)$ & & & \\
\hline $\mathrm{O}$ & 0 & 0 & $0.5 \mathrm{~d}$ & $0.5 \mathrm{~d}$ & 0 & 0 & $-(2 P / \pi \mathrm{d} t)$ & $6 P / \pi \mathrm{d} t$ & \\
\hline A & $0.25 \mathrm{~d}$ & 0 & $0.559 \mathrm{~d}$ & $0.559 \mathrm{~d}$ & 26.57 & 26.57 & $-(0.72 P / \pi \mathrm{d} t)$ & $3.12 P / \pi \mathrm{d} t$ & \\
\hline B & 0 & $0.25 \mathrm{~d}$ & $0.75 \mathrm{~d}$ & $0.75 \mathrm{~d}$ & 0 & 0 & $-(2 P / \pi \mathrm{d} t)$ & $8.66 P / \pi \mathrm{d} t$ & \\
\hline $\mathrm{C}$ & $0.5 \mathrm{~d}$ & 0 & $0.707 \mathrm{~d}$ & $0.707 \mathrm{~d}$ & 45 & 45 & 0 & 0 & \\
\hline $\mathrm{E}$ & 0 & $0.5 \mathrm{~d}$ & 0 & $\mathrm{~d}$ & 0 & 0 & $-(2 P / \pi \mathrm{d} t)$ & Stress concentration & \\
\hline
\end{tabular}

TABLE 5: Results of splitting test of marbles.

\begin{tabular}{|c|c|c|c|c|c|c|c|}
\hline $\begin{array}{l}\text { Sample } \\
\text { no. }\end{array}$ & $\begin{array}{l}\text { Diameter, } d \\
(\mathrm{~mm})\end{array}$ & $\begin{array}{l}\text { Height, } h \\
\quad(\mathrm{~mm})\end{array}$ & $\begin{array}{l}\text { Failure load, } P \\
(\mathrm{kN})\end{array}$ & $\begin{array}{l}\text { Tensile strength, } \sigma_{t} \\
(\mathrm{MPa})\end{array}$ & $\begin{array}{c}\text { Tensile modulus, } E_{t} \\
(\mathrm{GPa})\end{array}$ & $\begin{array}{l}\text { Modulus 2, } E_{2} \\
(\mathrm{GPa})\end{array}$ & Remarks \\
\hline 18 & 49.18 & 26.23 & 17.45 & 8.61 & 19.39 & 26.82 & \\
\hline 19 & 49.20 & 25.35 & 9.407 & 4.80 & 18.82 & 21.42 & \\
\hline 20 & 48.96 & 25.10 & 15.96 & 8.27 & 17.37 & 17.67 & \\
\hline 21 & 49.12 & 25.63 & 11.72 & 5.93 & 13.88 & 11.11 & \\
\hline 22 & 49.10 & 25.35 & 13.71 & 7.01 & 22.53 & -34.38 & \\
\hline 23 & 49.00 & 25.26 & 19.62 & 10.09 & 16.15 & -41.97 & \\
\hline
\end{tabular}

Description: (1) elastic modulus $E_{t}$ is the ratio of tensile stress to tensile strain in the $x$ direction at the point at the center of the circle, which is the tensile elastic modulus. (2) Elastic modulus $E_{2}$ is the ratio of stress to strain at another point of the sample (or the $y$ direction of the point at the center of the circle), and the negative value is expressed as the compressive modulus. (3) Each sample has 4 strain gauges, 2 on the front and back planes, and the corresponding positions are connected in series $(240 \Omega)$ for measurement.

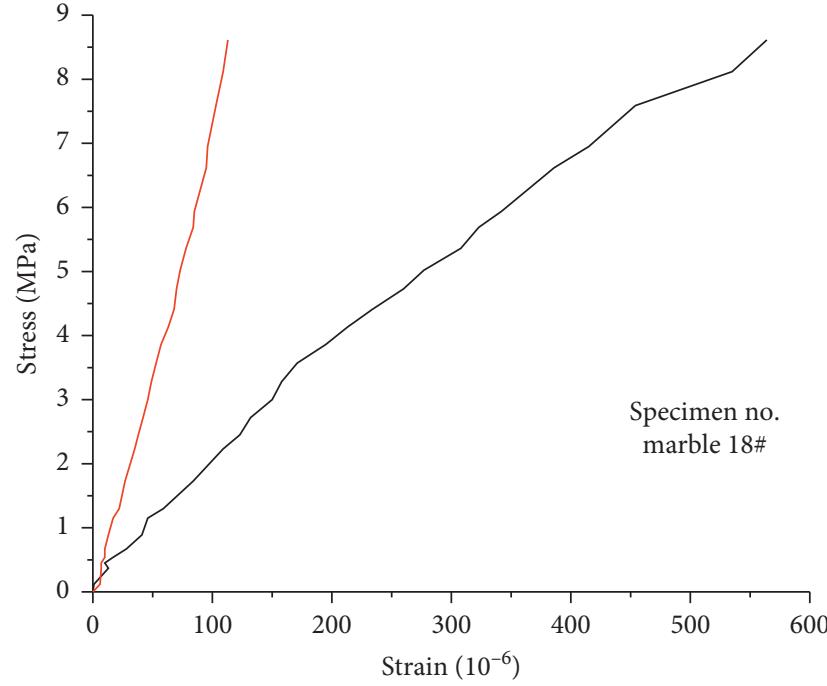

Position 1\#

Position 2\#

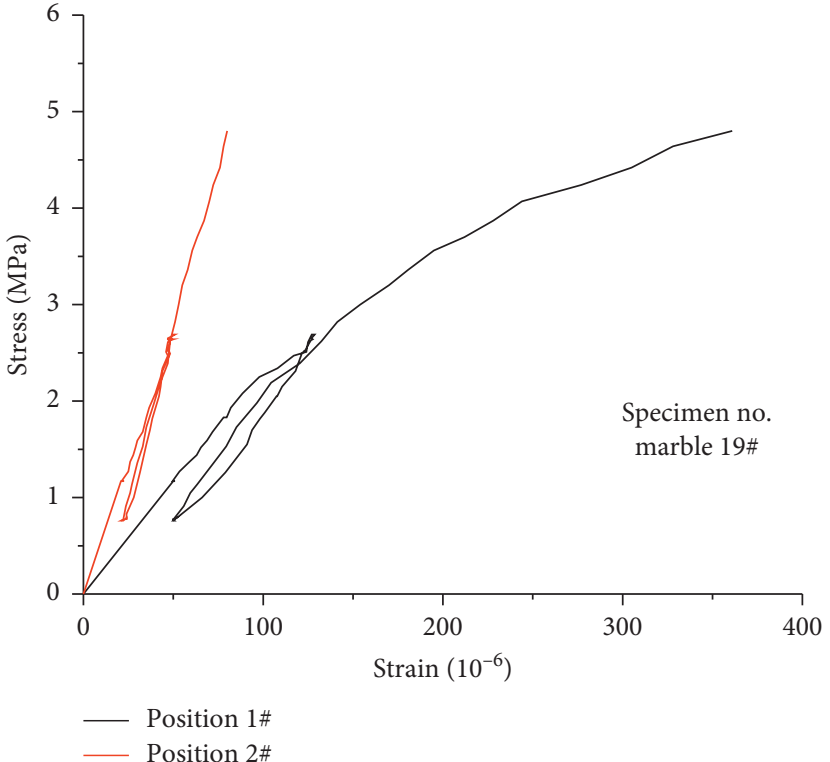

(b)

Figure 6: Continued. 


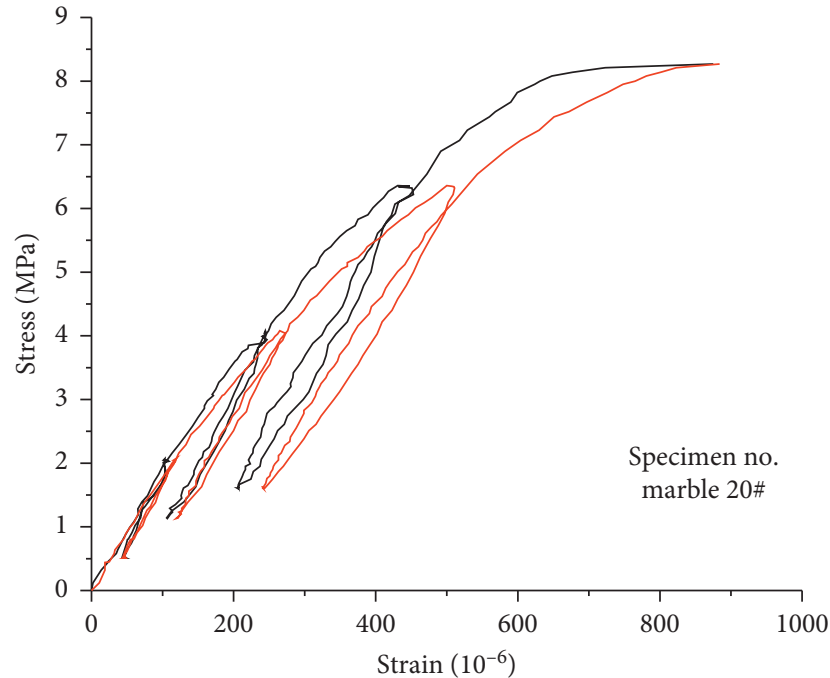

- Position 1\#

— Position 2\#

(c)

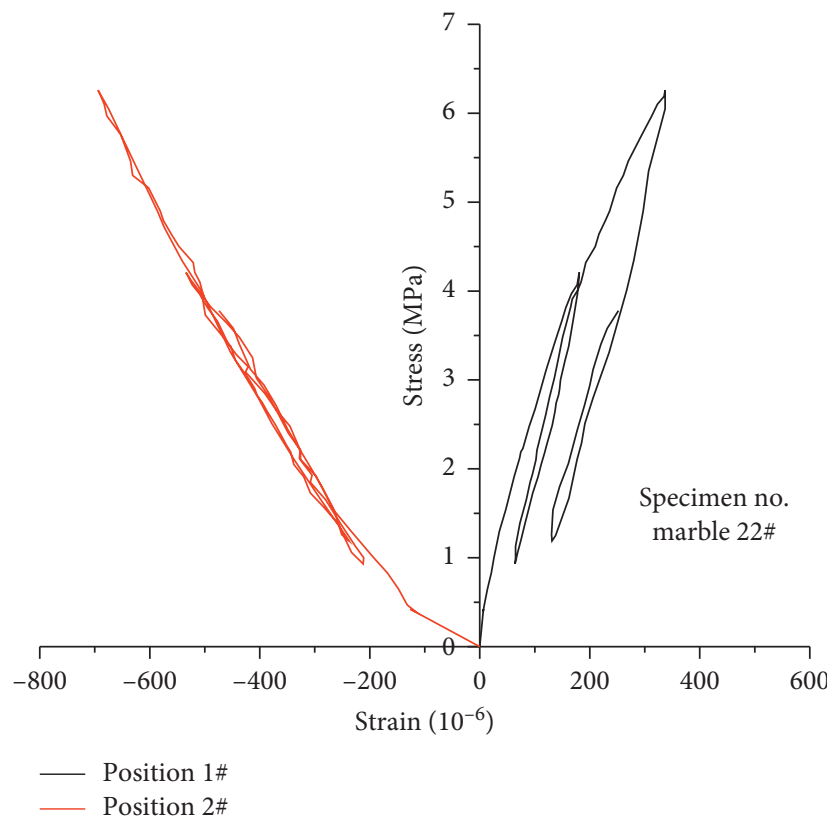

(e)

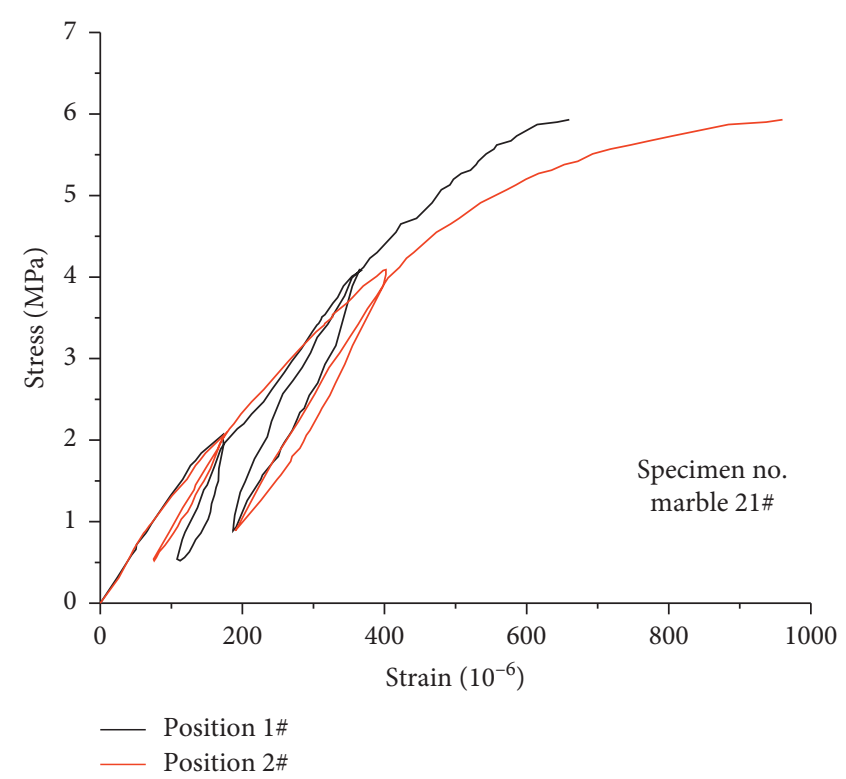

(d)

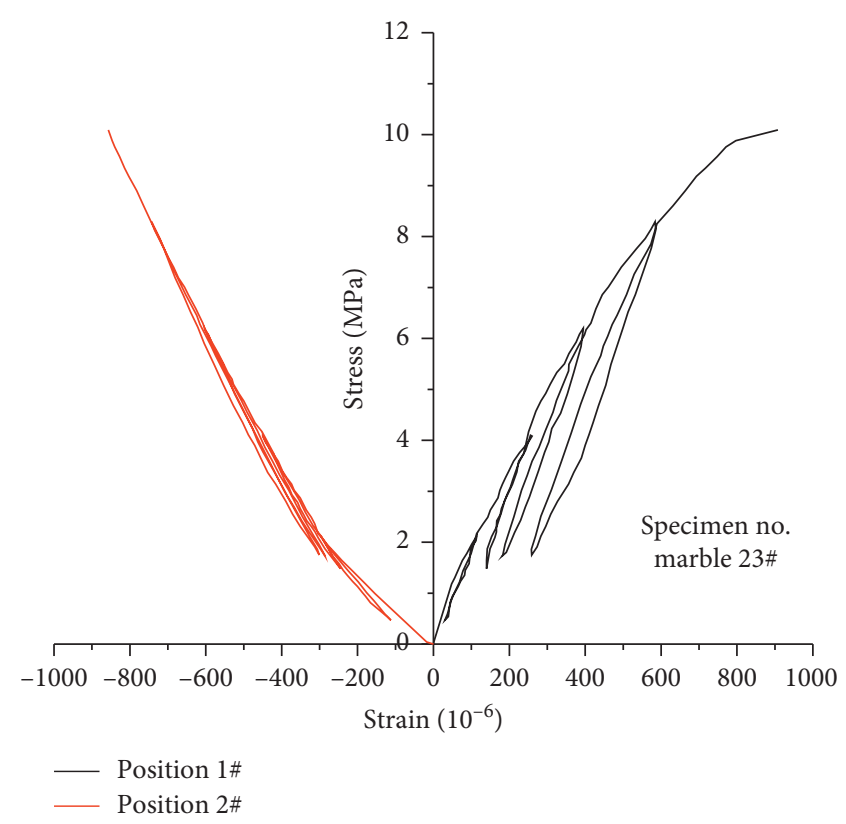

(f)

FiguRE 6: Stress-strain curves of rock samples at different positions in the marble splitting test (position 1 and position 2 are described in Figures 4 and 7(b)). (a) Marble 18\#. (b) Marble 19\#. (c) Marble 20\#. (d) Marble 21\#. (e) Marble 22\#. (f) Marble 23\#.

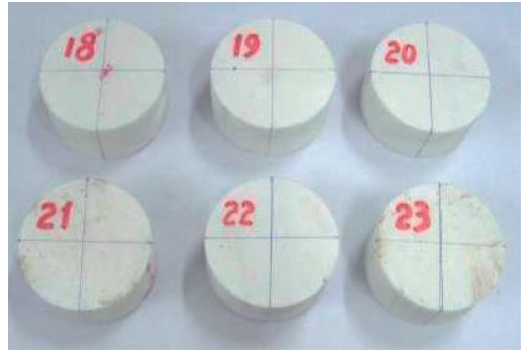

(a)

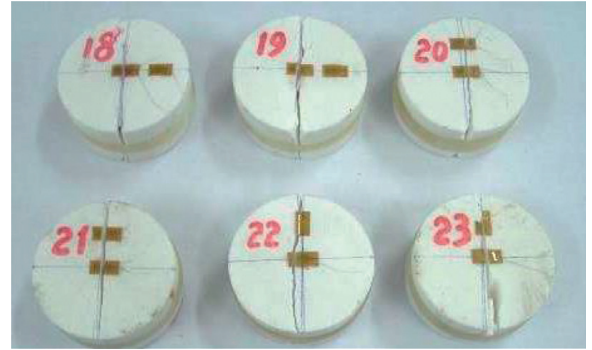

(b)

Figure 7: Pictures of before and after the failure of the samples with strain measurement at different positions in the Brazilian splitting tests. (a) Before the test. (b) After the test. 
TABLE 6: Results of direct tensile test of marbles.

\begin{tabular}{lccccccc}
\hline $\begin{array}{l}\text { Sample } \\
\text { no. }\end{array}$ & $\begin{array}{c}\text { Diameter, } d \\
(\mathrm{~mm})\end{array}$ & $\begin{array}{c}\text { Height, } h \\
(\mathrm{~mm})\end{array}$ & $\begin{array}{c}\text { Tensile failure } \\
\text { area, } A_{t}\left(\mathrm{~mm}^{2}\right)\end{array}$ & $\begin{array}{c}\text { Failure load, } \\
P(\mathrm{kN})\end{array}$ & $\begin{array}{c}\text { Tensile strength, Tensile modulus, Modulus 2, } E_{2} \\
\sigma_{t}(\mathrm{MPa})\end{array}$ & $\begin{array}{c}E_{t}(\mathrm{GPa}) \\
(\mathrm{GPa})\end{array}$ & $\begin{array}{c}\text { Remarks } \\
2\end{array}$ \\
\hline 1 & 49.17 & 103.44 & 1142 & 6.58 & 5.76 & 22.58 & 2.24 \\
2 & 48.75 & 103.28 & 1179 & 7.09 & 6.02 & 39.15 & - \\
3 & 49.21 & 103.99 & 1355 & 7.04 & 5.20 & 28.78 & 28.45 \\
4 & 49.13 & 103.30 & 1248 & 7.02 & 5.62 & 32.00 & - \\
5 & 49.36 & 102.12 & 1232 & 7.45 & 6.05 & 32.87 & - \\
6 & 49.18 & 101.22 & 1208 & 6.73 & 5.58 & 33.03 & - \\
\hline
\end{tabular}

Description: (1) elastic modulus $E_{t}$ is the ratio of tensile stress to tensile strain in the middle of the rock sample, which is the tensile elastic modulus; (2) elastic modulus $E_{2}$ is the ratio of stress to strain at another point of the sample ( $20 \mathrm{~mm}$ upper of the middle of the sample); (3) each sample has 4 strain gauges, 2 on the front and back planes, and the corresponding positions are connected in series $(240 \Omega)$ for measurement.

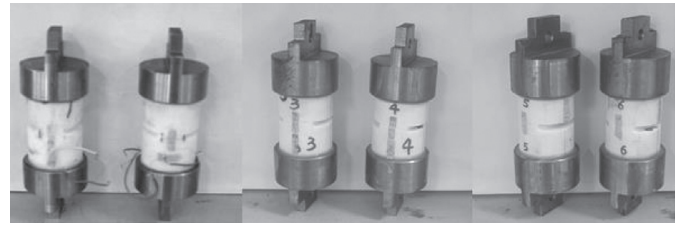

(a)

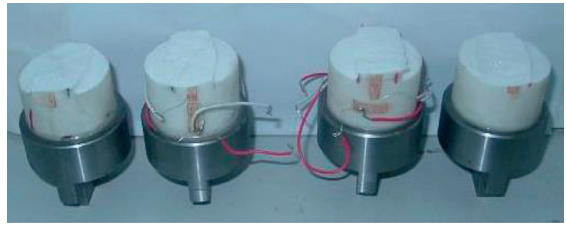

(b)

FIGURE 8: Photos of some samples before and after the direct tensile test of marbles. (a) Before the test. (b) After the test.

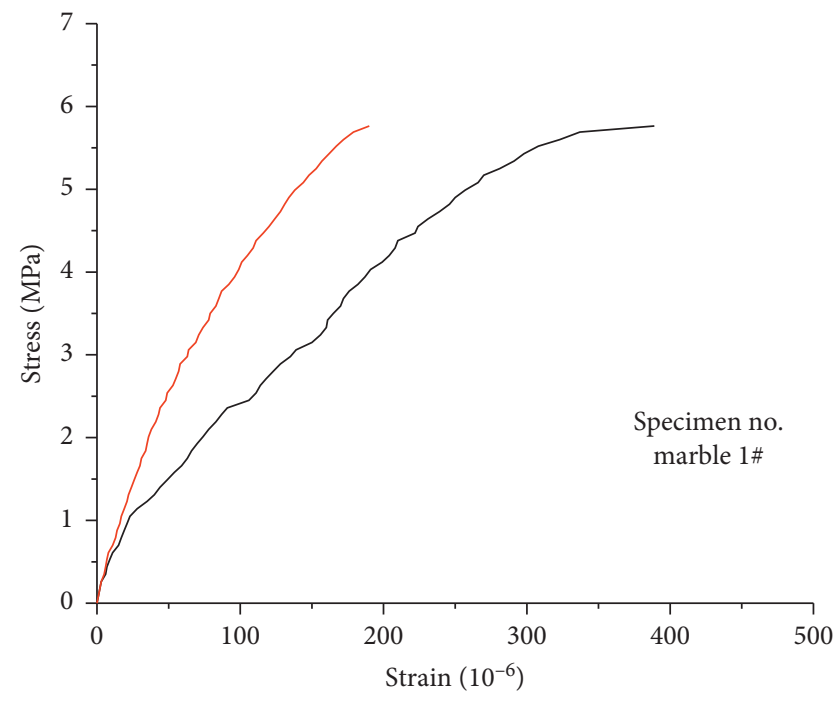

Position $1 \#$

Position 2\#

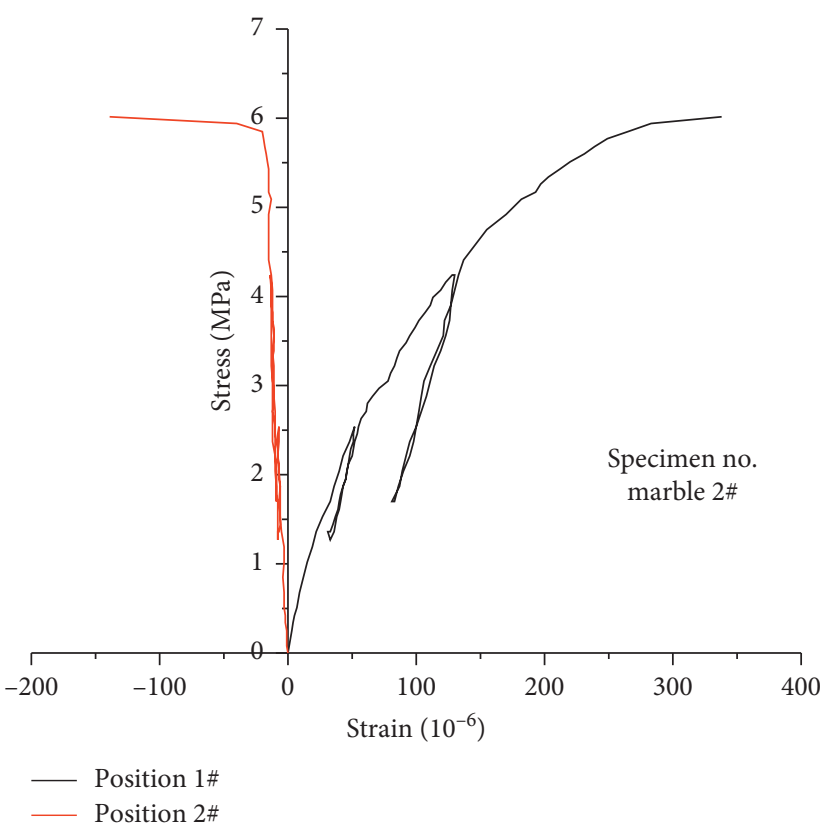

(b)

FIgURE 9: Continued. 


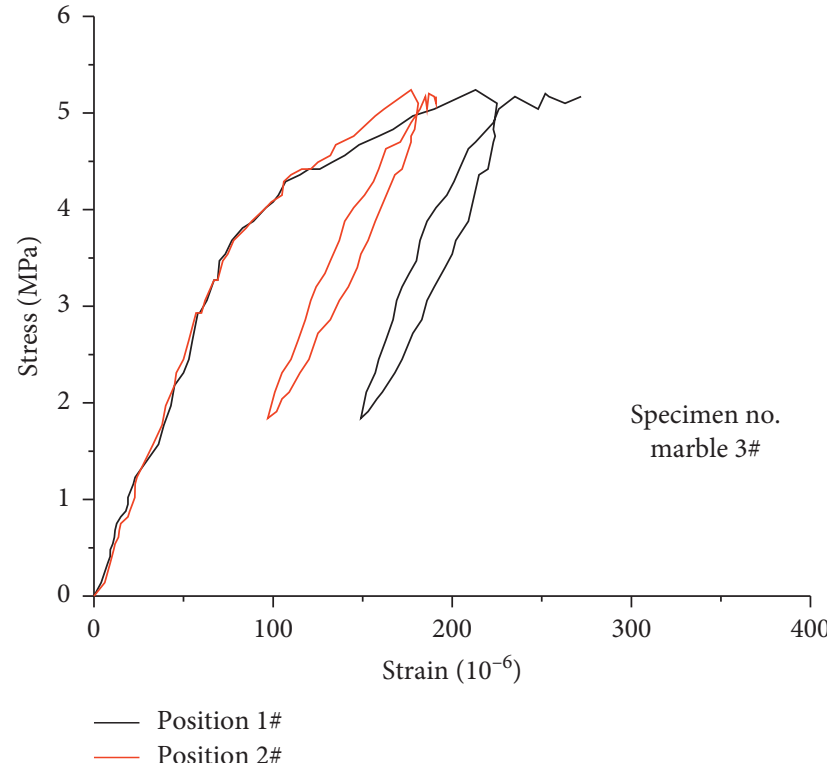

(c)

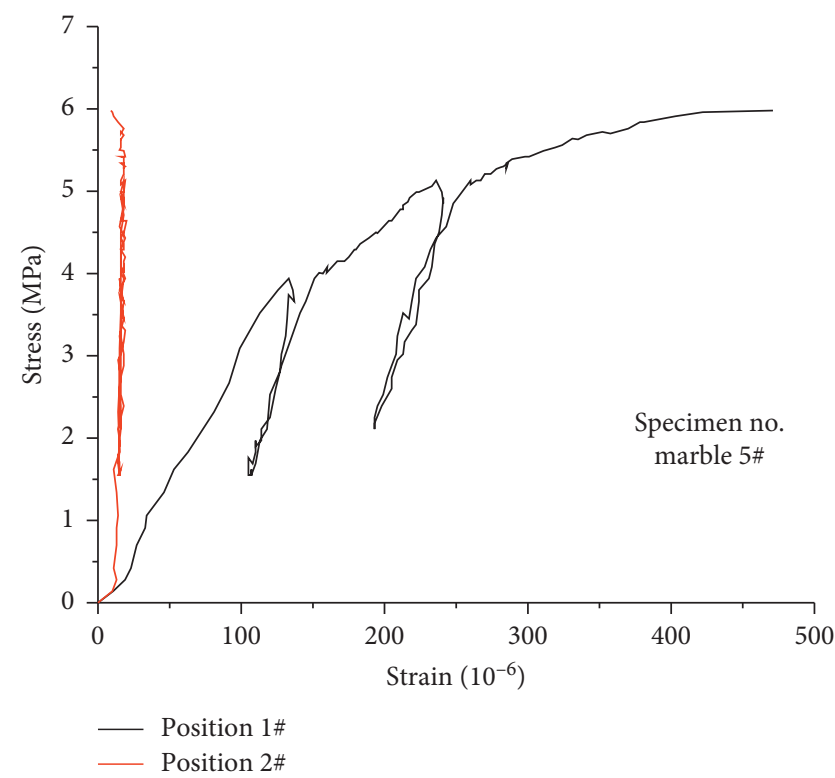

(e)

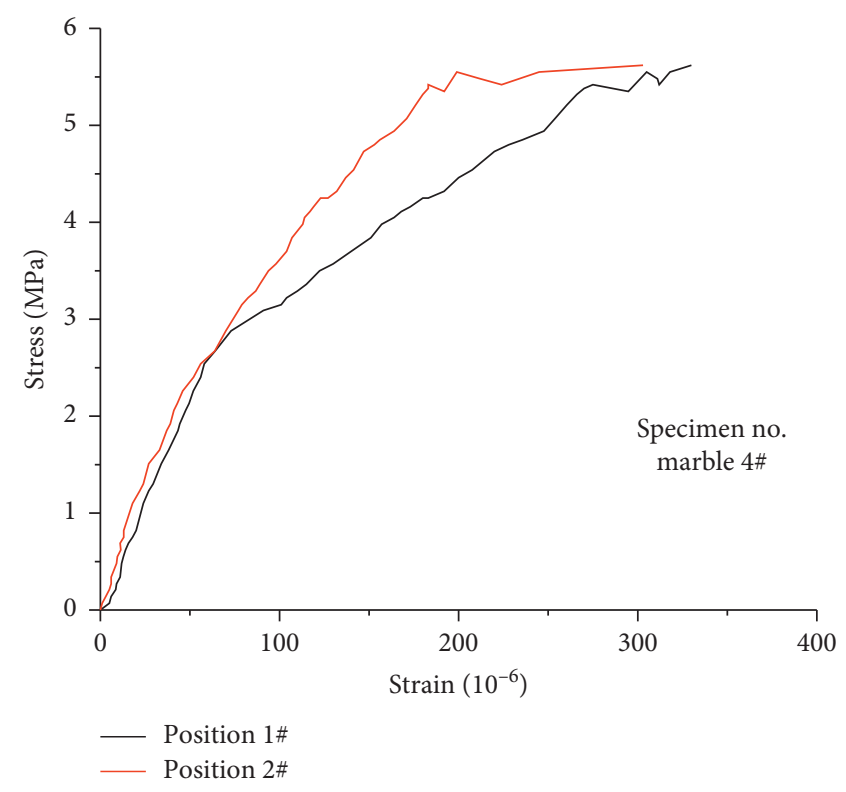

(d)

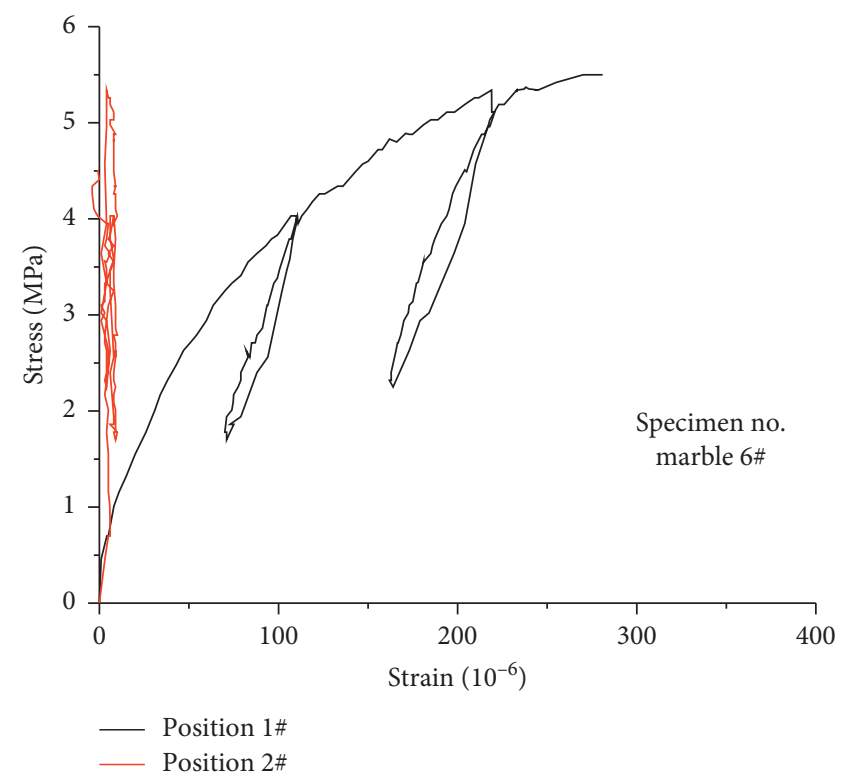

(f)

FiguRE 9: Stress-strain curve of the marble sample in direct tensile (position 1 and position 2 are as the descriptions in Figures 3 and 8(a)). (a) Marble 1\#. (b) Marble 2\#. (c) Marble 3\#. (d) Marble 4\#. (e) Marble 5\#. (f) Marble 6\#.

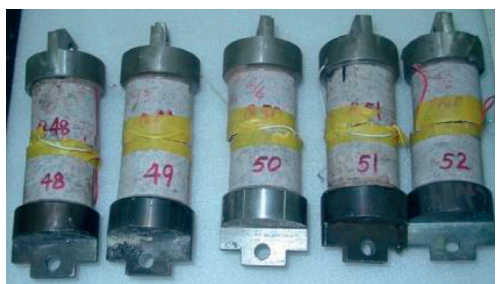

(a)

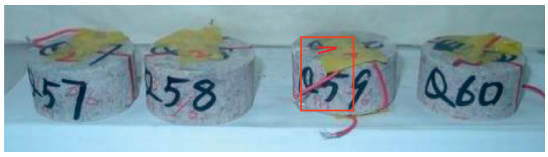

(b)

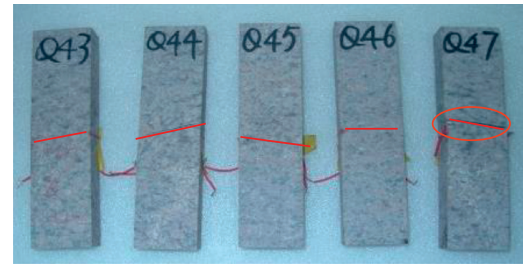

(c)

Figure 10: Rock samples after failure during the test. (a) Direct tensile test. (b) Brazilian splitting test. (c) Three-point bending test. 
discrete element numerical simulation and the RFPA finite element numerical test software to simulate the fracture process of rock samples in the different tests. Table 7 illustrates the numerical parameters of PFC.

Figure 11 shows the comparison of the stress-strain curves during the PFC simulations and the actual test, indicating that the test and simulation curves with the three methods are basically similar, and the simulated loading test has a high accuracy and rationality. It should be mentioned that, the strain in the simulations is based on a single particle element at the center of the samples, while the strain measured in experimental tests is obtained by the strain gauge attached to a grid area of $3 \times 10 \mathrm{~mm}$, which might lead to the difference of the stress-strain curves between experiments and simulations.

Figures 12-14 represent the partial damage development process of the rock samples in the direct tensile, disc splitting, and three-point bending simulation tests. Figure 15 reveals the relationship between the stress, the number of internal cracks, and the strain of the rock samples under the three methods. Figure 12 together with Figure 15(a) indicates that the damage of the rock sample is mainly caused by the crystal chain fracture between the mineral composition structures generated under the tensile stress. The microcracks begin to increase at the two ends of the prefabricated cracks and then expand towards the middle at about $95 \%$ of the peak stress, lastly increasing in a linear way with the stress. However, at the postpeak stage, the internal cracks rise rapidly as the stress falls. The cracks at both ends continually expand to the middle of the specimen, finally forming a main crack, but the internals will stop increasing once the stress drops to about $50 \%$ of the peak.

Figures 13 and 15(b) show that in the disc splitting tests, microcracks expose at about $70 \%$ of the peak stress and are all asymmetrically distributed at the upper and lower loading ends, which might be caused by the compression fracture of weak structural chains under the concentrated load. The number of internal fissures multiplies with the nonlinear increase of stress until it reaches a peak. At $95 \%$ of the peak stress, the rock reaches its ultimate bearing state and the number of internal cracks turns to rapidly increase. In this stage, the cracks are mainly concentrated at the two loadings, distributed in a "V" shape, while some sporadic small cracks can be found in the center of the rock sample. As the load continues, the cracks at the ends keep the rapid increase towards the middle curvilinear (Figure 13(b)), where the stress falls sharply; the strain increases greatly and the internal fissures of the rock sample multiply (Figure 15(b)). Finally, a nonlinear failure surface is formed by the increasingly jointed cracks, when the rock sample is completely fractured. It is noted that the final form confirms the results of the experimental test.

Figures 14 and 15(c) exhibit that the first cracks mainly appear at the upper loading point and the bottom two fulcrums in the three-point bending test, while more microcracks are concentrated at the upper, which might be produced by the stress concentration. When the bottom stress exceeds the tensile strength of the rock, cracks will turn to expose on the left side of the bottom middle of the sample. Then, as the stress decreases, the cracks gradually expand obliquely up to the direction of the upper loading point, until finally penetrated. Figure 15(c) reveals the sharp increase of the fractures in the rock sample at the moment of the final fracturing. The entire damage process indicates a nonlinear trend and a modest increase of microcracks before the peak stress. Besides, the approximately oblique straight line of the final fracture surface expresses its consistency with the indoor test results in Figure 10(c). However, as far as the direct tensile test is discussed, the increase of microcracks is initiated when the stress reaches about $95 \%$ of the peak, while the growth of microcracks begins at about $85 \%$ of the peak. It is suggested that more experiments on different rocks will contribute to a systematic monitoring of the internal damage during loading as well as a better understanding of the initiating, expanding, and forming processes of microcracks with different tensile testing methods.

Figures 16-19 demonstrate the relationships between rock sample stress, acoustic emission and strain, and the partial evolution process of the maximum principal stress and acoustic emission using the RFPA numerical simulation test. In direct tensile tests, when the stress is close to the peak, it causes acoustic emission signals at the tip of the prefabricated crack in the middle. With the stress transferring towards the middle, more cracks generate and expand until the complete fracturing of rock by penetration. Besides, the acoustic emission signal keeps its rapid increase at the tip of the central fracture and expands towards the middle. Note that the energy influence area radius of the newly created fracture's acoustic emission signal is significantly larger than that of the previous fracture.

In the disc splitting tests, this signal appears earlier, approximately at $27 \%$ of the peak stress, while the number of the acoustic emission events is small and grows slowly. When the stress reaches about $80 \%$ of the peak, the events in the middle of the rock begin to increase with a horizontal $\mathrm{V}$-shaped distribution and then continue growing rapidly with the stress and expand towards the loading ends until at the ends forms a V-shaped concentrated area and in the middle a curve shape. We propose that the stress concentration at the two loading ends results in the compression fracture and the formed fracture surface evidences the results of the indoor test.

Nevertheless, in the three-point bending test, the acoustic emission signal comes at about $22 \%$ of the peak, located on the left side of the rock bottom, which might be caused by the fracture of the weak crystal chain under tensile stress. When the stress reaches about $60 \%$ of the peak, acoustic emission signals occur in the middle of the rock bottom, with a small number of the emissions. At $92 \%$ of the peak stress, the middle acoustic emission events increase at the bottom and continue the growth until the stress reaches the peak, where they gather around the right of the center and tend to expand diagonally up to the loading point. Subsequently, the internal acoustic emission events grow in the same and sometimes the opposite way with the stress. This indicates that the damage of rock in the three-point bending test is caused fully by tensile failure. 
TABLE 7: Mesomechanical parameters of the parallel bonded particle model.

\begin{tabular}{lcccccccccccc}
\hline Lithology & $R_{\min }(\mathrm{mm})$ & $R_{\max }(\mathrm{mm})$ & $\rho\left(\mathrm{kg} \cdot \mathrm{m}^{-3}\right)$ & $\mu$ & $E^{*}(\mathrm{GPa})$ & $k_{\mathrm{r}}$ & $\bar{E}^{*}(\mathrm{GPa})$ & $\lambda$ & $n$ & $\bar{\sigma}_{c} \mathrm{MPa}$ & $\bar{c} \mathrm{MPa}$ & $\bar{\phi}\left({ }^{\circ}\right)$ \\
\hline Granite & 0.8 & 1.33 & 2.619 & 0.5 & 42 & 1 & 42 & 1 & 0.36 & 8.7 & 37 & 20 \\
Marble & 0.8 & 1.33 & 2.835 & 0.5 & 88.16 & 1 & 88.16 & 1 & 0.36 & 19 & 15 & 20 \\
Diabase & 0.8 & 1.33 & 2.144 & 0.5 & 49 & 1 & 49 & 1 & 0.36 & 12 & 10 & 20 \\
\hline
\end{tabular}

Note. $R_{\min }$ is the minimum particle radius, $R_{\max }$ is the max particle radius, $\rho$ is the particle bulk density, $n$ is the porosity, $\mu$ is the friction coefficient, $\lambda$ is the radius multiplier, $\bar{E}^{*}$ is the parallel bond Young's modulus, $E^{*}$ is the particle contact Young's modulus, $k_{r}$ is the ratio of stiffness, $\bar{\sigma}_{c}$ is the parallel bond tensile strength, $\bar{c}$ is the parallel bond cohesion, and $\bar{\phi}$ is the friction angle.

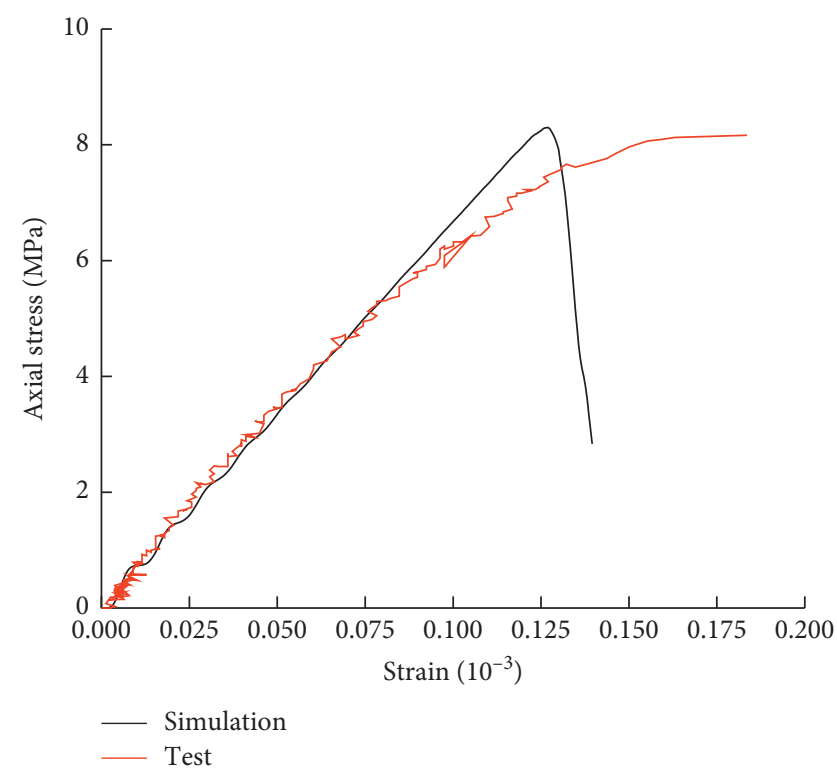

(a)

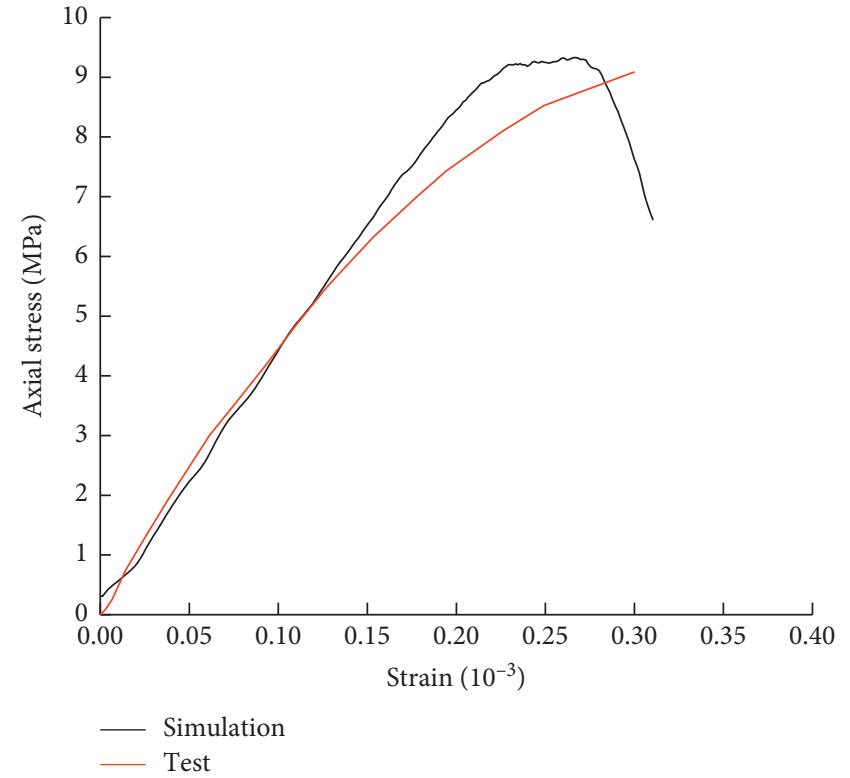

(b)

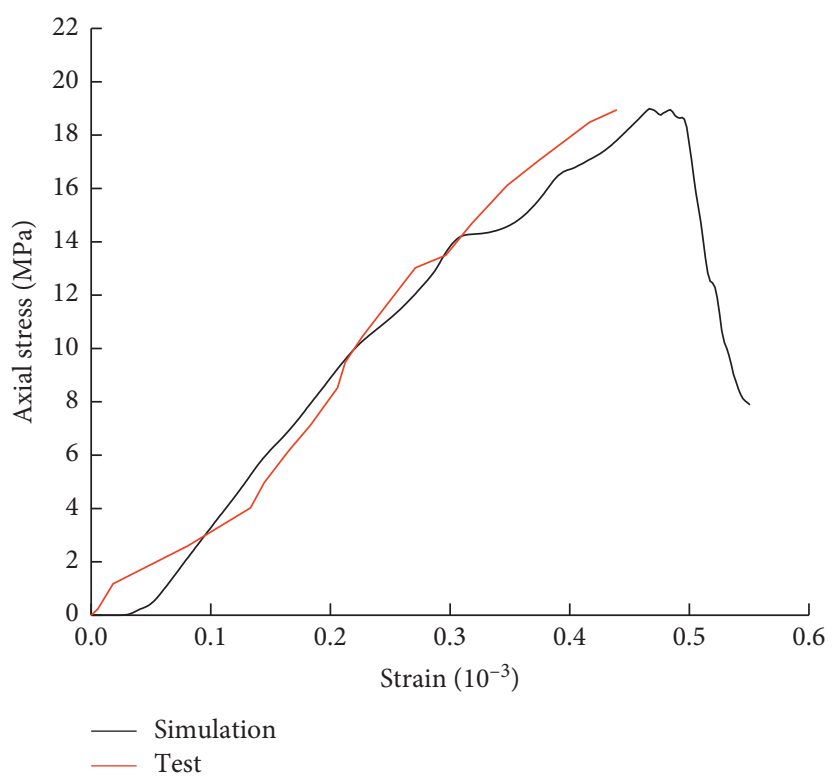

(c)

FIGURE 11: Comparison of PFC simulation and indoor test results with different methods. (a) Comparison of direct tensile. (b) Comparison of disc splitting. (c) Comparison of three-point bending. 


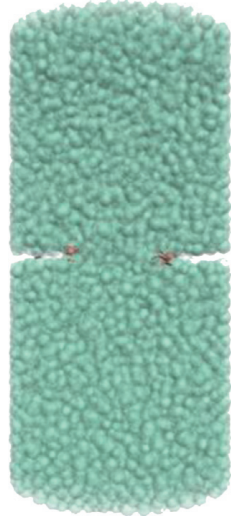

(a)

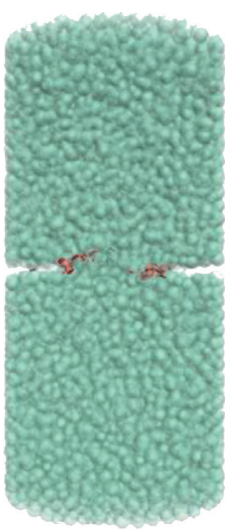

(b)

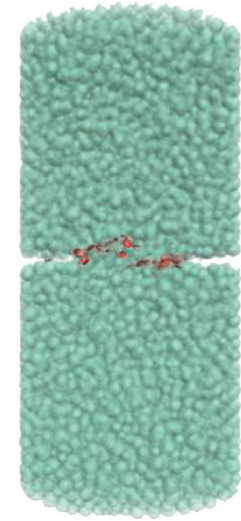

(c)

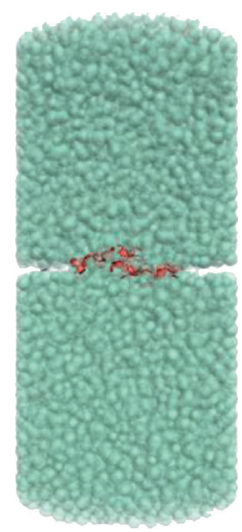

(d)

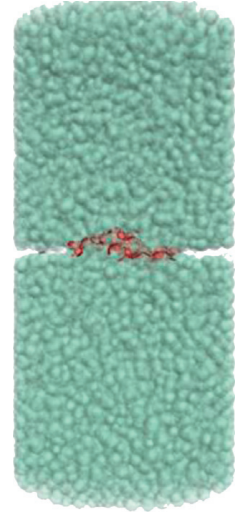

(e)

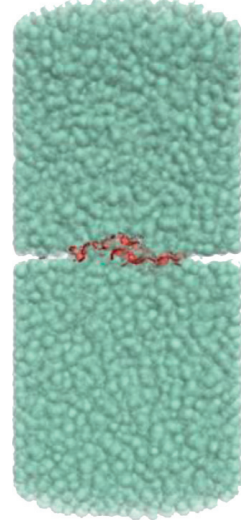

(f)

FiguRE 12: Development process of rock sample failure in direct tensile. (a) 64, 8.01 MPa. (b) 108, 8.25 MPa. (c) 207, 8.22 MPa. (d) 325, $7.54 \mathrm{MPa}$. (e) 430, 5.15 MPa. (f) 443, 2.84 MPa.

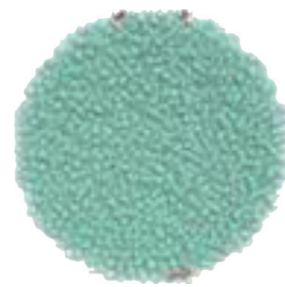

(a)

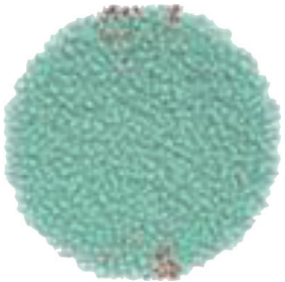

(b)

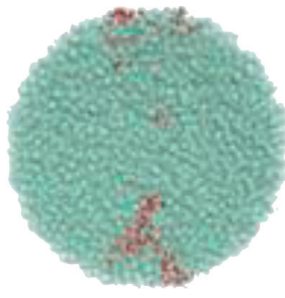

(c)

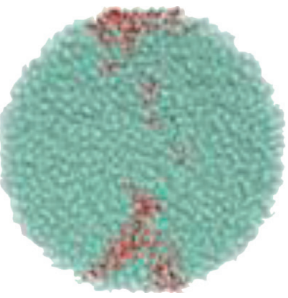

(d)

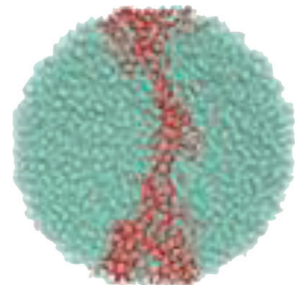

(e)

FiguRE 13: Development process of rock failure in Brazilian splitting. (a) 37, 6.81 MPa. (b) 192, 8.67 MPa. (c) 527, 9.21 MPa. (d) 880, 9.27 MPa. (e) 3187, 6.60 MPa.

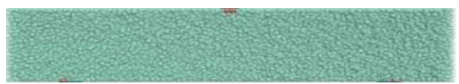

(a)

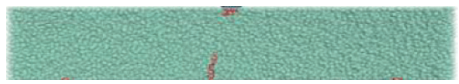

(d)

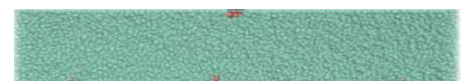

(b)

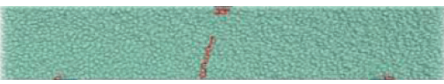

(e)

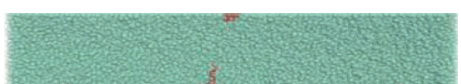

(c)

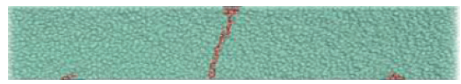

(f)

Figure 14: Rock failure development process in three-point bending. (a) 84, 17.96 MPa. (b) 192, 17.0 MPa. (c) 286, 12.3 MPa. (d) 372 , 8.47 MPa. (e) $576,7.286 \mathrm{MPa}$. (f) $899,5.9 \mathrm{MPa}$.

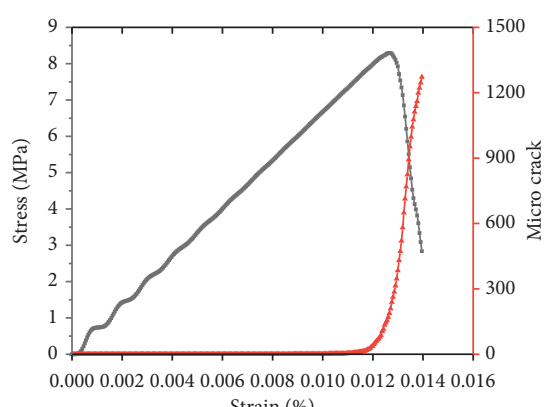

Strain $(\%)$

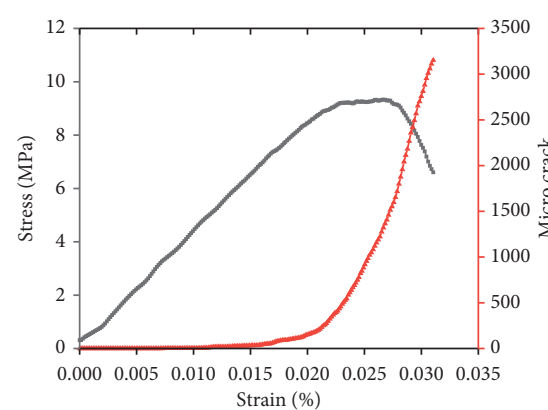

- Stress

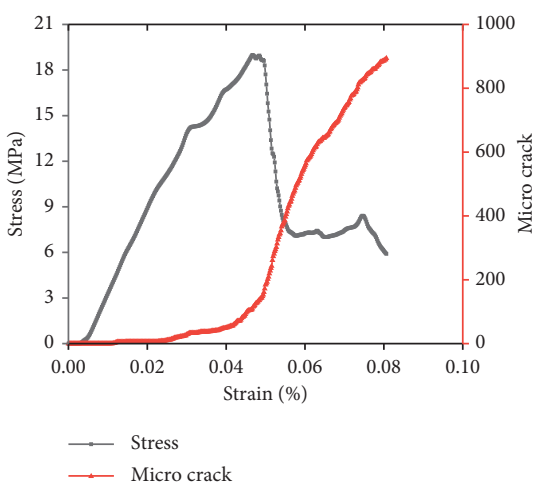

(c)

(a)

(b)

FIGURE 15: Relationship curve of stress, microcracks, and strain in rock test. (a) Direct tensile. (b) Disc splitting. (c) Three-point bending. 


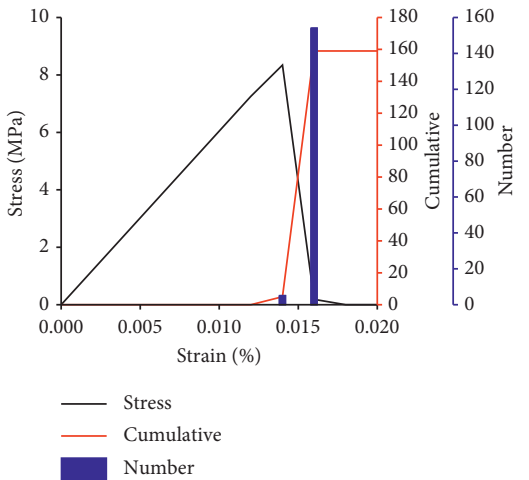

(a)
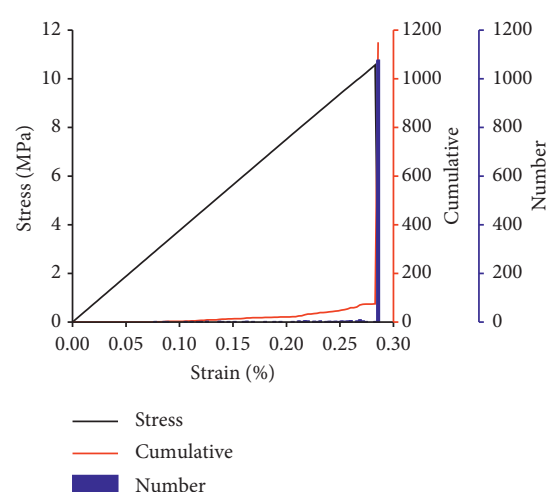

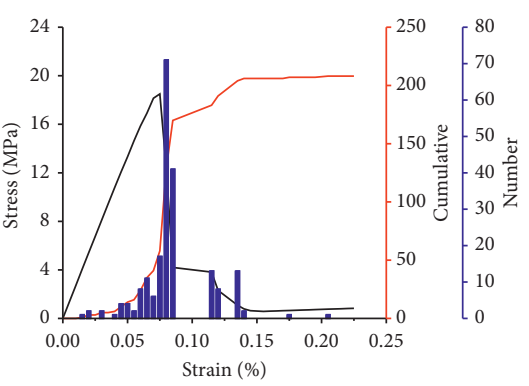

- Stress Number

(b)

(c)

Figure 16: Relationship between stress and acoustic emission characteristics and strain during the RFPA simulation test. (a) Direct tensile. (b) Disc splitting. (c) Three-point bending.

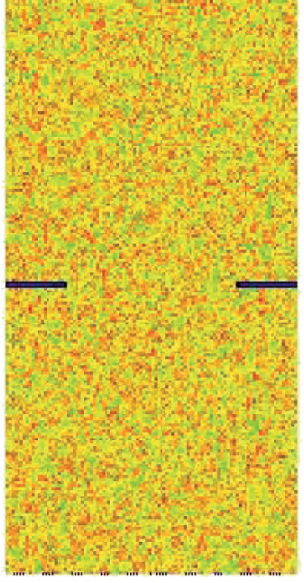

(a)

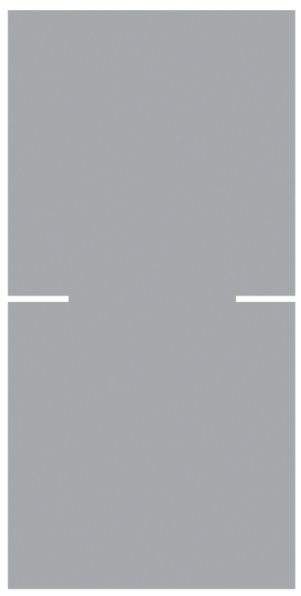

(f)

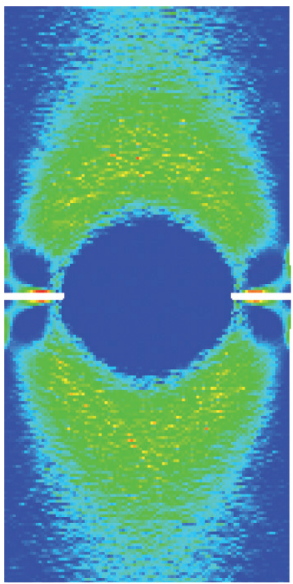

(b)

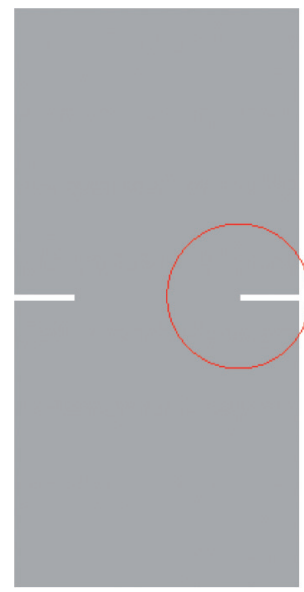

(g)

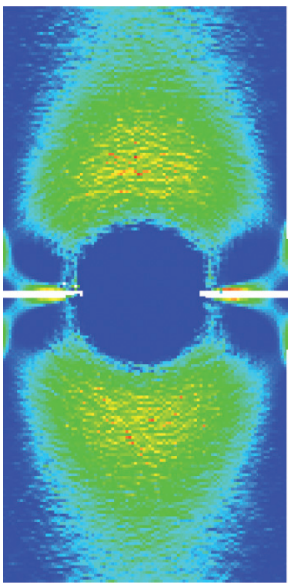

(c)

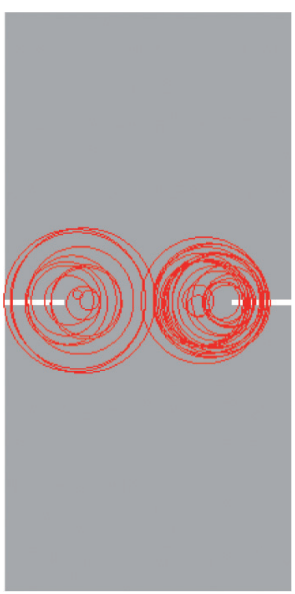

(h)

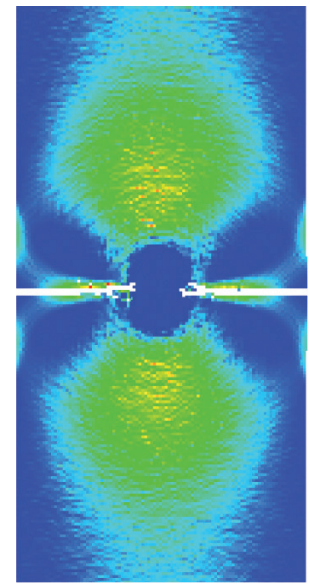

(d)

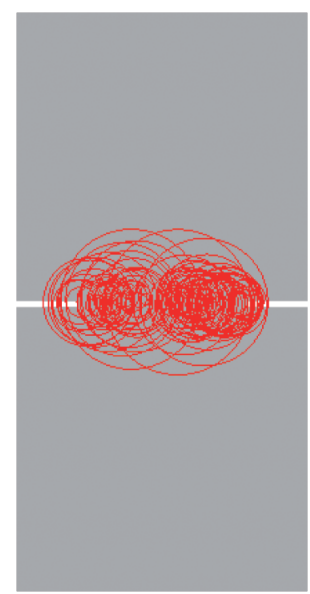

(i)

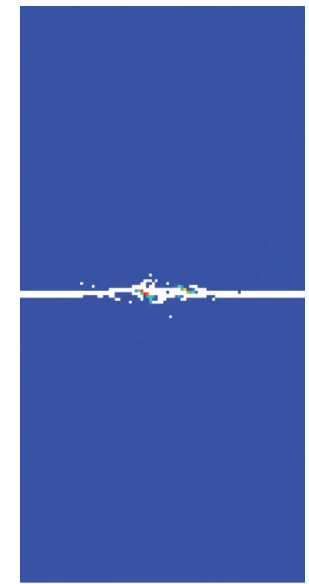

(e)

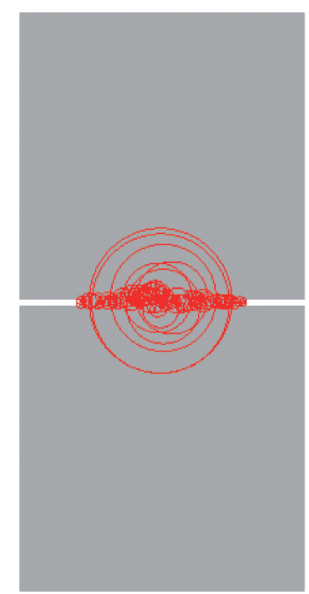

(j)

FIGURE 17: Development process of rock sample failure and AE indirect tensile. 


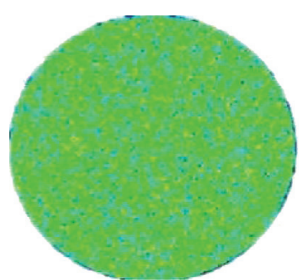

(a)

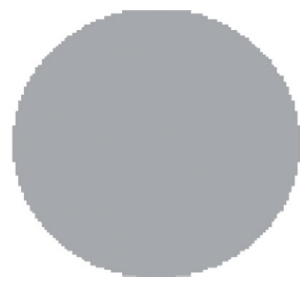

(f)

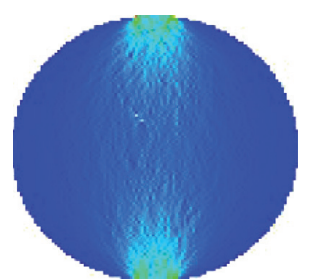

(b)

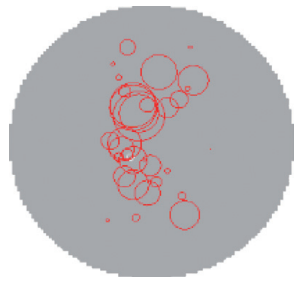

(g)

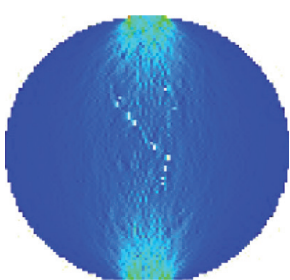

(c)

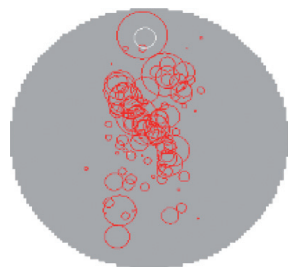

(h)

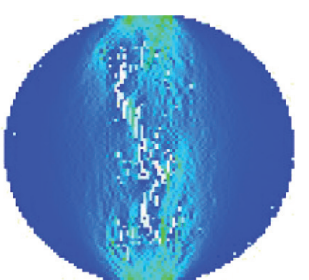

(d)

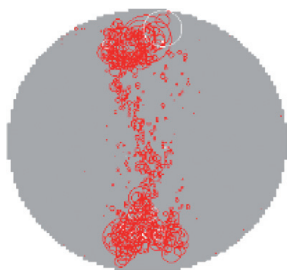

(i)

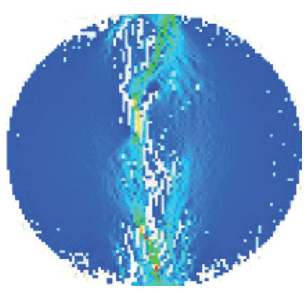

(e)

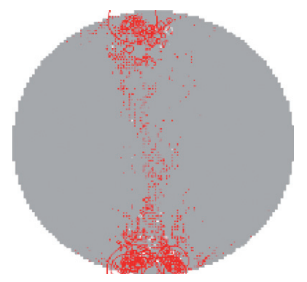

(j)

Figure 18: Development process of rock failure and AE in Brazilian splitting.

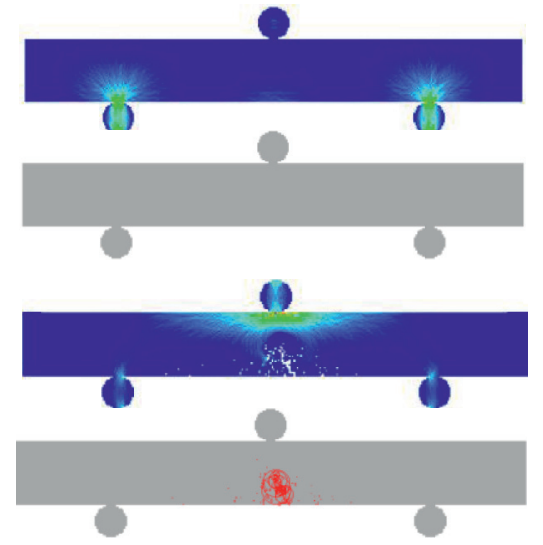

(a)

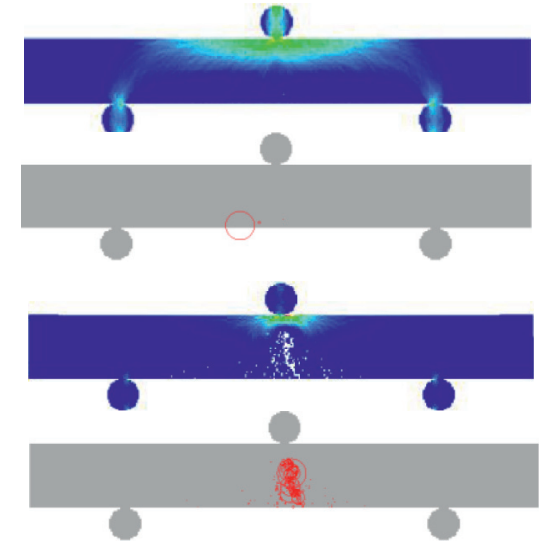

(b)

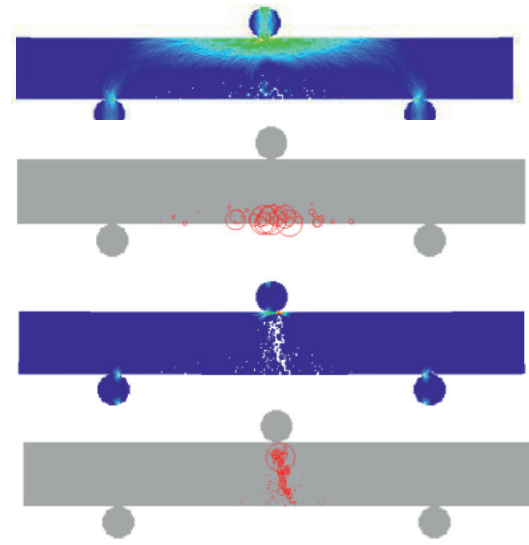

(c)

FIGURE 19: Development process of rock failure and AE in three-point bending.

\section{Conclusions}

In this study, we employed three testing methods of direct tensile, Brazilian splitting, and three-point bending on marble, granite, and diabase to investigate their strength, modulus, and stress-stain characteristics as well as their relationship. The conclusions can be confirmed as follows:

(1) The measured strength in Brazilian splitting tests is $10 \%$ greater than the actual value, while the modulus is lower than its actual value. The strength in the three-point bending test is about 1.6 to 2.8 times of that in the direct tensile, with the rock sample is fractured by the combined tensile and compressive loads in the former test.

(2) With respect to the stress-stain characteristics, in the splitting test, the tensile modulus in the direction vertical to loading is almost not changed, but smaller than the compressive modulus. Besides, the strength of the same group of rocks varies from different specimens. In the direct tensile test, the strain values keep the same at the same height, while the deformation around the prenotch is much smaller than that away from it.

(3) Rocks in direct tensile tests are all fractured from the prefabricated cracks, with a basically flat surface. In Brazilian splitting tests, the main cracks are slightly curvilinear shaped, with a clearly "V"-shaped compression failure zones in the loading areas at both ends, while they are oblique-line in the three-point bending tests.

(4) PFC and RFPA modelling of numerical simulation tests is suggested to simulate and analyze the initiating, cracking, multiplying, and penetrating processes of rock cracks with different testing methods, and the simulation results on the failure mode are in a general agreement with the experimental. The 
stress level for microcracks' initiation in the splitting and bending tests is lower than that in the direct tensile test, despite more microcracks.

\section{Data Availability}

The data used to support the findings of the study are included in the article.

\section{Conflicts of Interest}

The authors declare that they have no conflicts of interest.

\section{Acknowledgments}

The authors gratefully acknowledge the financial support from the National Natural Science Foundation of China (Grant no. 51774022) and the National Key R\&D Program Project of China (Grant no. 2018YFE0101100).

\section{References}

[1] S. Zhang, X. Miao, and H. Zhao, "Influence of test methods on measured results of rock tensile strength," Journal of China University of Mining \& Technology, vol. 28, no. 3, pp. 243-246, 1999.

[2] X. Song, Dynamic Split Tension Strength of Marble and the Properties of Crack Initiation and Crack Propagation under Dynamic Split tests, University of Sichuan, Chengdu, China, 2005.

[3] W. Jiong, W. Zhu, R. Li, L. Niu, and Q. Wang, "Experiment of the tensile strength and fracture toughness of rock using notched three point bending test," Journal of Water Resources and Architectural Engineering, vol. 14, no. 3, pp. 128-132, 2016.

[4] H. Wang, H. Liu, M. Zhang, and X. Wang, "Experimental study on calculation of the uniaxial compressive strength and tensile ttrength of granite based on the point load tests," Chinese Journal of Underground Space and Engineering, vol. 9, no. S1, pp. 1498-1501, 2013.

[5] ISRM, "Suggested methods for determining tensile strength of rock materials," International Journal of Rock Mechanics and Mining Sciences \& Geomechanics Abstracts, vol. 15, pp. 99103, 1978.

[6] B. Zhao, D. Liu, and X. Kaixi, "Experimental study on direct tensile properties of red sandstone in Chongqing," Geotechnical Investigation \& Surveying, vol. 4, pp. 9-12, 2011.

[7] S. Klanphumeesri, Direct Tension Testing of Rock Specimens, Suranaree University of Technology, Nakhon Ratchasima, Thailand, 2010.

[8] X. Zhang, Q. Zhang, S. Yuan, C. Wang, and Q. Gao, "Development of test device for direct axial tension on rock and its application," Chinese Journal of Rock Mechanics and Engineering, vol. 33, no. 12, pp. 2517-2523, 2014.

[9] J. A. Hudson, E. T. Brown, and F. Rummel, "The controlled failure of rock discs and rings loaded in diametral compression," International Journal of Rock Mechanics and Mining Sciences \& Geomechanics Abstracts, vol. 9, no. 2, pp. 241-248, 1972.

[10] A. Coviello, R. Lagioia, and R. Nova, "On the measurement of the tensile strength of soft rocks," Rock Mechanics and Rock Engineering, vol. 38, no. 4, pp. 251-273, 2005.
[11] M. A. Perras and M. S. Diederichs, "A review of the tensile strength of rock: concepts and testing," Geotechnical and Geological Engineering, vol. 32, no. 2, pp. 525-546, 2014.

[12] Y. Yu, "Questioning the validity of the Brazilian test for determining tensile strength of rocks," Chinese Journal of Rock Mechanics and Engineering, vol. 24, no. 7, pp. 1150-1157, 2005.

[13] Y. Yu and P. Chen, "Spatial distribution of tensile stress in Brazilian disk test of rock," Rock and Soil Mechanics, vol. 26, no. 12, pp. 1913-1916, 2005.

[14] M. He, J. Hu, W. Xiong, and C. Liu, "Splitting test and analysis of rock tensile strength," Mining Research and Development, vol. 25, no. 2, pp. 12-16, 20105.

[15] Y. G. Huang, L. G. Wang, J. R. Chen, and J. H. Zhang, "Theoretical analysis of flattened Brazilian splitting test for determining tensile strength of rocks," Rock and Soil Mechanics, vol. 36, no. 3, pp. 739-748, 2015.

[16] J. Chen, "Bending test for tensile strength of rock samples," Journal of Engineering Geology, vol. 16, pp. 317-319, 2008.

[17] Y. Tong, B. Wang, Q. Gao, and L. Xiao, "Study on bending tensile tests of rock samples," Site Investigation Science and Technology, vol. 6, pp. 3-5, 2004.

[18] A. Z. Lv, H. Y. Wang, and H. Cai, "A new method for determination of uniaxial tensile strength of rock through bending test," Chinese Journal of Underground Space and Engineering, vol. 14, no. 6, pp. 1452-1457, 2018.

[19] X. Xi, X. Wu, Q. Guo, and M. Cai, "Experimental investigation and numerical simulation on the crack initiation and propagation of rock with pre-existing cracks," IEEE Access, vol. 8, pp. 129636-129644, 2020.

[20] X. Xi, Z. Yin, S. Yang, and C.-Q. Li, "Using artificial neural network to predict the fracture properties of the interfacial transition zone of concrete at the meso-scale," Engineering Fracture Mechanics, vol. 242, Article ID 107488, 2021.

[21] F. Kittitep and K. Sippakorn, "Laboratory determination of direct tensile strength and deformability of intact rocks," Geotechical Testing Journal, vol. 31, no. 1, pp. 1-6, 2011.

[22] Z. Wang, "Test on tensile strength of rectangular rock specimen," Chinese Journal of Underground Space and Engineering, vol. 11, no. 2, pp. 370-374, 2015.

[23] Q. Dou, S. Yue, and G. Dai, "Comparative study of rock direct tensile test and split test," Underground Space, vol. 24, no. 2, pp. 178-181, 2004.

[24] N. Erarslan, Z. Z. Liang, and D. J. Williams, "Experimental and numerical studies on determination of indirect tensile strength of rocks," Rock Mechanics \& Rock Engineering, vol. 45, no. 5, pp. 739-751, 2012.

[25] D. Duan, C. Tang, T. Xu, W. Jiang, and Z. Zhang, "Numerical simulation of indirect tensile tests for rock," Metalmine, vol. 4, pp. 12-15, 2007.

[26] R. Ulusay and J. A. Hudson, "The complete ISRM suggested methods for rock characterization, testing and monitoring: 1974-2006," Journal of Rock Mechanics \& Mining Sciences, vol. 46, no. 8, pp. 1396-1397, 2009.

[27] SL/T 264-2020, Rock Test Regulations for Water Conservancy and Hydropower engineering, China Water Power Press, Beijing, China, 2020.

[28] GB/T20266-2013, Engineering Rock Mass Test Method Standard, China Planning Press, Beijing, China, 2013.

[29] Z. Huang, F. Ren, L. Yuan, D. Zhang, Z. Sui, and Y. Zhang, "Tensile strength and damage characteristics of rock under different test methods," Experimental Technology and Management, vol. 37, no. 10, pp. 45-49, 2020. 